\title{
Interphase chemistry of Si electrodes used as anodes in Li-ion batteries
}

\author{
Catarina Pereira-Nabais ${ }^{\mathrm{a}, \mathrm{b}}$, Jolanta Światowska ${ }^{\mathrm{a}, *}$, Alexandre Chagnes ${ }^{\mathrm{b}, *}$, François Ozanam ${ }^{\mathrm{c}}$, \\ Aurélien Gohier ${ }^{\mathrm{d}, \mathrm{e}}$, Pierre Tran-Van ${ }^{\mathrm{e}}$, Costel-Sorin Cojocaru ${ }^{\mathrm{d}}$, Michel Cassir ${ }^{\mathrm{b}}$, Philippe Marcus ${ }^{\mathrm{a}}$
}

${ }^{a}$ Laboratoire de Physico-Chimie des Surfaces, Chimie ParisTech - CNRS (UMR 7045), Ecole Nationale Supérieure de Chimie de Paris, 11 rue Pierre et Marie Curie, 75005 Paris, France ${ }^{b}$ Laboratoire d'Electrochimie, Chimie des Interfaces et Modélisation pour l'Energie, Ecole Nationale Supérieure de Chimie de Paris Chimie ParisTech - CNRS (UMR 7575), 11 rue Pierre et Marie Curie, 75005 Paris, France

${ }^{\mathrm{c}}$ Laboratoire de Physique de la Matière Condensée, École Polytechnique-CNRS (UMR 7643), Route de Saclay, 91128 Palaiseau, France

${ }^{\mathrm{d}}$ Laboratoire de Physique des Interfaces et Couches Minces, École Polytechnique - CNRS (UMR 7647), Route de Saclay, 91128 Palaiseau, France

${ }^{\mathrm{e}}$ Renault Research Department, 1 avenue du Golf, 78288 Guyancourt, France

\begin{abstract}
a b s t r a c t
The effect of the Si electrode morphology (amorphous hydrogenated silicon thin films - a-Si:H as a model electrode and Si nanowires - SiNWs electrode) on the interphase chemistry was thoroughly investigated by the surface science techniques: X-ray photoelectron spectroscopy (XPS) and time-of-flight secondary ion mass spectrometry (ToF-SIMS). XPS analysis shows a strong attenuation and positive shift of the Si $2 p$ peaks after a complete charge/discharge performed in PC- and EC:DMC-based electrolytes for both electrodes (a-Si:H and SiNW), confirming a formation of a passive film (called solid electrolyte interphase - SEI layer). As evidenced from the XPS analysis performed on the model electrode, the thicker SEI layer was formed after cycling in PC-based electrolyte as compared to EC:DMC electrolyte. XPS and ToF-SIMS investigations reveal the presence of organic carbonate species on the outer surface and inorganic salt decomposition species in the inner part of the SEI layer. Significant modification of the surface morphology for the both electrodes and a full surface coverage by the SEI layer was confirmed by the scanning electron microscopy (SEM) analysis.
\end{abstract}

\section{Introduction}

In the last decade, many efforts have been made to increase the energy density of lithium-ion batteries (LiB), namely for electric vehicle applications. One way to improve the energy density of a battery is to use high specific capacity materials, e.g. the elements (M) from the IV-A or V-A column of the periodic table. These elements (M) are well known to form very rich-lithium compounds such as $\mathrm{Li}_{4.4} \mathrm{M}$ and $\mathrm{Li}_{3} \mathrm{M}$, respectively [1], at very low potentials close to the lithiation of graphite, which also contributes to the increase of the energy density of the battery. Among them, silicon is the most attractive one due to its low molecular weight $(28 \mathrm{~g} / \mathrm{mol})$ and the possibility of forming $\mathrm{Li}_{22} \mathrm{Si}_{5}$ alloy $(\mathrm{Li} / \mathrm{Si}=4.4)$ according to the Li-Si phase diagram [2,3]. Si can also form lower Li content $\mathrm{Li}-\mathrm{Si}$ phases in the very early stages of silicon lithiation such as $\mathrm{Li}_{13} \mathrm{Si}_{4}$ $(\mathrm{Li} / \mathrm{Si}=3.25), \mathrm{Li}_{7} \mathrm{Si}_{4}(\mathrm{Li} / \mathrm{Si}=1.75)$, and $\mathrm{Li}_{12} \mathrm{Si}_{7}(\mathrm{Li} / \mathrm{Si}=1.71)$. Theoretically, $\mathrm{Li}_{22} \mathrm{Si}_{5}$ can deliver a specific capacity of $4200 \mathrm{mAh} / \mathrm{g}$, which is 10 times higher than graphite electrode $(372 \mathrm{mAh} / \mathrm{g})$. Nevertheless, volume variation during lithiation is the major drawback of $\mathrm{Li}-\mathrm{Si}$

) alloys as it can reach $310 \%$ for $\mathrm{Li}_{22} \mathrm{Si}_{5}$, whereas only $10 \%$ of volume variation is observed for $\mathrm{LiC}_{6}$ [4]. It has been reported that $\mathrm{Li}-\mathrm{Si}$ electrochemical alloying at room temperature and at potentials lower than $50 \mathrm{mV}$ leads to silicon amorphisation [5] and the formation of crystalline $\mathrm{Li}_{15} \mathrm{Si}_{4}$ (specific capacity $=3600 \mathrm{mAh} / \mathrm{g}$ ) which does not exist in the reported Li-Si phase diagram [6-9]. Volume variation causes mechanical stresses that involve morphological damages of the electrode material (electrode pulverisation and formation of small particles) responsible for loss of electrical contact between the particles and the current collector. Morphological damages of electrode materials during alloying-de-alloying can be avoided by using nanosized materials, which allow better accommodation of volume variation, such as Si nanowires (NW) [10-13]. However, a huge capacity loss (irreversible capacity) of about $30 \%$ has been observed during the first charge (lithiation). A capacity fade of $10 \%$ observed between 0.6 and $0.5 \mathrm{~V}$ can be attributed to the formation of a solid electrolyte interphase (SEI) layer, while a fade of $10 \%$ was assigned to electrical loss of the electroactive material [14]. The composition of the SEI layer depends on the nature of the solvent/salt system [15-17]. Numerous papers report that the SEI layer formed onto graphite-type negative electrode in carbonate solvent containing lithium salts is mainly constituted of lithium alkyl carbonates, lithium carbonate and lithium inorganic salts [18]. However, very few papers refer to the formation of 
the SEI layer on silicon electrodes [11,19-25], because it was first believed that no SEI layer was formed [26]. Extensive study of cyclability of pure Si electrodes [10-12,27] was an incentive to study and to understand the formation of the SEI layer during the first cycle of charge/discharge on silicon nanowires (SiNW) and hydrogenated amorphous silicon (a-Si:H) electrodes. The a-Si:H thin film was used as a model electrode to study the SEI formation on SiNW, since a flat surface is more appropriate for the qualitative and quantitative analysis by means of surface sensitive techniques like X-ray photoelectron spectroscopy (XPS) and time-of-flight secondary ion mass spectrometry (ToF-SIMS).

\section{Experimental}

\subsection{Electrode preparation}

The same stainless steel (SS) substrate (50/Lm thickness, AISI321, Goodfellow) was used for deposition of a thin layer of hydrogenated amorphous silicon $(\mathrm{a}-\mathrm{Si}: \mathrm{H})$ and silicon nanowires (SiNW). Before deposition the SS substrate was degreased in deionised water/TFD4 detergent solution and then washed with deionised and millipore water.

Before deposition of a thin layer of hydrogenated amorphous silicon (a-Si:H), the SS substrate was treated with hydrogen $\left(\mathrm{H}_{2}\right)$ plasma. A thin layer of hydrogenated amorphous silicon (a-Si:H) was deposited on the substrate heated at $250{ }^{\circ} \mathrm{C}$ by rf plasmaassisted chemical vapour deposition (PECVD) of $\mathrm{SiH}_{4}$ gas. The rf frequency, power, pressure and flow rate during a-Si:H deposition were $13.56 \mathrm{MHz}, 0.10 \mathrm{~W} \mathrm{~cm}^{-2}, 0.5 \mathrm{mbar}$ and $33 \mathrm{sccm}$, respectively. After $1.5 \mathrm{~min}$ of deposition, a bluish coloured $30 \mathrm{~nm}$ thick layer was obtained. The specific weight of the active material was estimated to $6 / \mathrm{Lg} / \mathrm{cm}^{2}$ considering the a-Si:H density of $2.2 \mathrm{~g} / \mathrm{cm}^{3}$.

Prior to CVD growth of SiNWs, $50 \mathrm{~nm}$ of Ti as adhesive layer and $100 \mathrm{~nm}$ of TiN as conductive diffusion barrier were deposited on the substrates, followed by a deposition of $10 \mathrm{~nm}$-thick Au film, using a magnetron sputtering system. The substrates were then loaded in a CVD furnace and heated under vacuum (base pressure less than $10^{-5}$ mbar) in order to transform the Au thin film into Au clusters of various sizes, to reduce the surface/interface energy with TiN. Then, the $\mathrm{Si}$ NW was grown by injection of the $\mathrm{SiH}_{4}$ gas diluted at $17 \%$ in dihydrogen $\left(\mathrm{H}_{2}\right)$ for $15 \mathrm{~min}$ at a total flow of $120 \mathrm{sccm}$ and pressure of $7.5 \mathrm{mbar}$ during $30 \mathrm{~min}$. The Si weight/surface ratio was estimated to be $260 / \mathrm{Lg} / \mathrm{cm}^{2}$.

\subsection{Electrochemical tests}

Cyclic voltammetry (CV) was carried out with a PGSTAT30 Autolab and a VMP3 Biologic multi-channel potentiostat/galvanostat, while data acquisition was done with GPES and EC-Lab softwares, respectively. The CV test was chosen as the most adequate technique for studying the reactions occurring at the electrode surface. The electrochemical tests were performed in a glove-box directly connected to the ultra-high vacuum XPS or ToF-SIMS analysis chamber to avoid contamination of cycled samples. The electrochemical tests were carried out in Teflon Swagelok half-cells (a-Si:H/Li metal or SiNW/Li metal) containing dried filter paper as a separator (only for propylene carbonate (PC)-based electrolyte) or Celgard ${ }^{\circledR} 2100$ (for ethylene carbonate (EC):dimethylcarbonate (DMC)-based electrolyte). The cyclic voltammetry was performed at room temperature at a scan rate of $20 / \mathrm{LV} \mathrm{s}^{-1}$ from the open circuit voltage (OCV) to $10 \mathrm{mV}$ and the reverse scan from $10 \mathrm{mV}$ to $2.5 \mathrm{~V}$ vs $\mathrm{Li}_{/} / \mathrm{Li}^{+}$. The samples were then relaxed to the OCV. At potentials lower than $50 \mathrm{mV}$, crystallisation of amorphous $\mathrm{Li}-\mathrm{Si}$ alloy into $\mathrm{Li}_{15} \mathrm{Si}_{4}$ and volume variation of about $270 \%$ are expected. The electrochemical tests were performed in propylene carbonate (PC, purity $>99.7 \%$, Sigma-Aldrich) in
$1 \mathrm{M} \mathrm{LiClO}_{4}$ (Aldrich, battery grade) or in a mixture of ethylene carbonate (EC, purity 99\%, Alfa Aesar) and dimethyl carbonate (DMC, purity $\geq 99 \%$, Sigma-Aldrich) [(EC:DMC) $=(1: 1)$ (wt:wt)] in $1 \mathrm{M} \mathrm{LiPF}_{6}$ (purity $>99.99 \%$, battery grade, Sigma-Aldrich). After cycling, the silicon electrodes were removed from Swagelok cells and washed with DMC to eliminate electrolyte contamination for further XPS, ToF-SIMS or SEM analyses. The potential was measured using lithium foil (99.9\% purity, Aldrich) as a reference electrode, so all potential values are referred to $\mathrm{Li} / \mathrm{Li}^{+}$.

\subsection{X-ray photoelectron spectroscopy (XPS)}

XPS analyses were carried out using a VG ESCALAB 250 spectrometer equipped with a UHV (Ultra High Vacuum) preparation chamber directly connected to the glove box [28]. The base pressure in the analysis chamber was approximately $10^{-9}$ mbar. An $\mathrm{Al} \mathrm{Ka}$ monochromatized radiation ( $\mathrm{hv}=1486.6 \mathrm{eV}$ ) was employed as X-ray source. For all analyses, the take-off angle of the photoelectrons was $90^{\circ}$. Survey scans and high resolution spectra were recorded with pass energy of 100 and $20 \mathrm{eV}$, respectively. Data processing (peak fitting) was performed with the Avantage software provided by Thermo Electron Corporation. Gaussian/Lorentzian (70\%/30\%) peak shapes were used and Shirley background subtraction was applied. Charge effects were corrected by setting the lower energy component of the $\mathrm{C} 1 \mathrm{~s}$ peak at $285.0 \mathrm{eV}$ or $\mathrm{Si} 2 \mathrm{p}$ at $99.3 \mathrm{eV}$. A Si $2 \mathrm{p}_{1 / 2}: \mathrm{Si} 2 \mathrm{p}_{3 / 2}$ peak area ratio was fixed to $1: 2$ (the theoretical value). During C 1s and $\mathrm{O}$ 1s peak decomposition a full width at half-maximum (FWHM) was fixed. The pristine samples were analysed as prepared, while cycled a-Si:H and SiNW samples were washed with DMC.

The thickness of $\mathrm{SiO}_{2}\left(\mathrm{~d}_{\mathrm{SiO}_{2}}\right)$ native oxide layer formed on the a-Si:H and SiNW was estimated using the following equation:

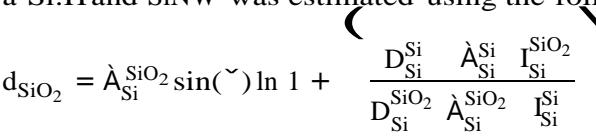

where $\grave{A}_{\mathrm{Si}}^{\mathrm{SiO}_{2}}, \grave{A}_{\mathrm{Si}}^{\mathrm{Si}}$ are the inelastic mean free paths of the photoelectrons emitted by the $\mathrm{Si}$ core level in the $\mathrm{SiO}_{2}$ and $\mathrm{Si}$ matrix, respectively, calculated from the TPP2 $\mathrm{M}$ formula $[29]\left(\hat{\mathrm{A}}_{\mathrm{Si}}^{\mathrm{SiO}_{2}}=\right.$ $3.12 \mathrm{~nm}, \grave{A}_{\mathrm{Si}}^{\mathrm{Si}}=3.08 \mathrm{~nm}$ ), (3 is the take off-angle of photoelectrons $\left(\left(3=90^{\circ}\right), \mathrm{D}_{\mathrm{Si}}^{\mathrm{Si}}\right.$ and $\mathrm{D}_{\mathrm{Si}}^{\mathrm{SiO}_{2}}$ denote the bulk concentrations of element $\mathrm{Si}$ and $\mathrm{SiO}_{2}$ in the matrix $\mathrm{Si}$ and $\mathrm{SiO}_{2}\left(\mathrm{D}_{\mathrm{Si}}^{\mathrm{SiO}_{2}}=4.995 \times 10^{22}\right.$ atoms $/ \mathrm{cm}^{3}, \mathrm{D}_{\mathrm{Si}}^{\mathrm{Si}}=2.656 \times 10^{22}$ atoms $\left./ \mathrm{cm}^{3}\right)$, and $\mathrm{I}_{\mathrm{Si}}^{\mathrm{SiO}}, \mathrm{I}_{\mathrm{Si}}^{\mathrm{Si}}$ are the intensities of the $\mathrm{SiO}_{2}$ and $\mathrm{Si}$ peaks.

\subsection{Time of flight secondary ion mass spectrometry (ToF-SIMS)}

A IONTOF ToF-SIMS 5 spectrometer (time-of-flight secondary ion mass spectrometry) was run at an operating pressure of $10^{-9}$ mbar. In the dual beam analysis mode a $25 \mathrm{keV} \mathrm{Bi}^{+}$analysis beam (analysis area $100 \times 100 / \mathrm{Lm}^{2}$ ) was combined with a $500 \mathrm{eV} \mathrm{Cs}^{+}$sputtering beam (sputtering area $300 \times 300 / \mathrm{Lm}^{2} \mathrm{Cs}^{+}$) for tracing in-depth profile concentration. The negatively charged secondary ions were analysed. The $\mathrm{Bi}^{+}$and $\mathrm{Cs}^{+}$currents were typically $1.4 \mathrm{pA}$ and $30 \mathrm{nA}$, respectively. Data acquisition and postprocessing analysis were done using the Ion-Spec software. The cycled samples were transferred directly from the glove-box to the ToF-SIMS spectrometer without exposition to ambient air.

\subsection{Field emission gun - scanning electron microscopy (FEG-SEM)}

FEG-SEM micrographs were obtained with a ZEISS scanning electron microscope equipped with an energy-dispersive $\mathrm{X}$-ray (EDX) analyser. 


\section{Results and discussion}

3.1. Electrochemical characterisation of a-Si:H thin films and SiNW.

Fig. 1a shows the first CVs of a-Si:H thin film and stainless steel substrate performed in $\mathrm{PC} / \mathrm{LiClO}_{4} 1 \mathrm{M}$. The differences between CVs for stainless steel and a-Si:H electrodes give evidence of the $\mathrm{Li}-\mathrm{Si}$ alloying reactions occurring with Si thin film electrodes. The CV

(a)

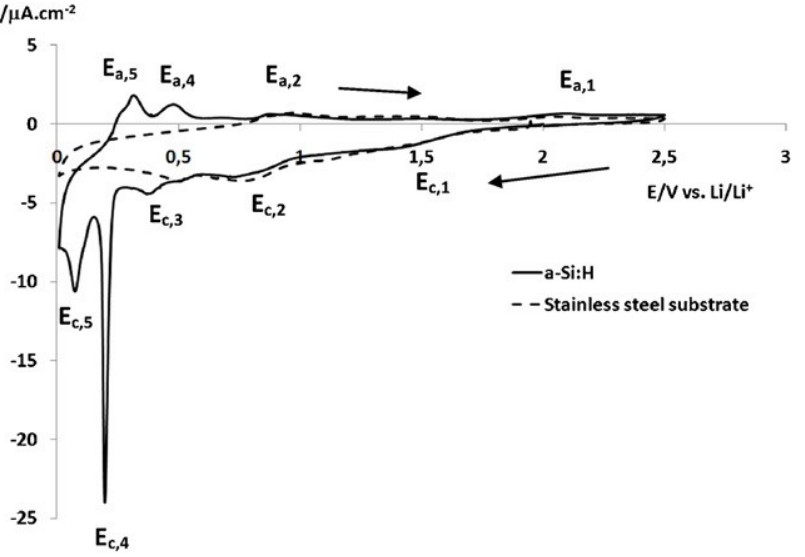

(b) $1 / \mu \mathrm{A} \cdot \mathrm{cm}^{2}$

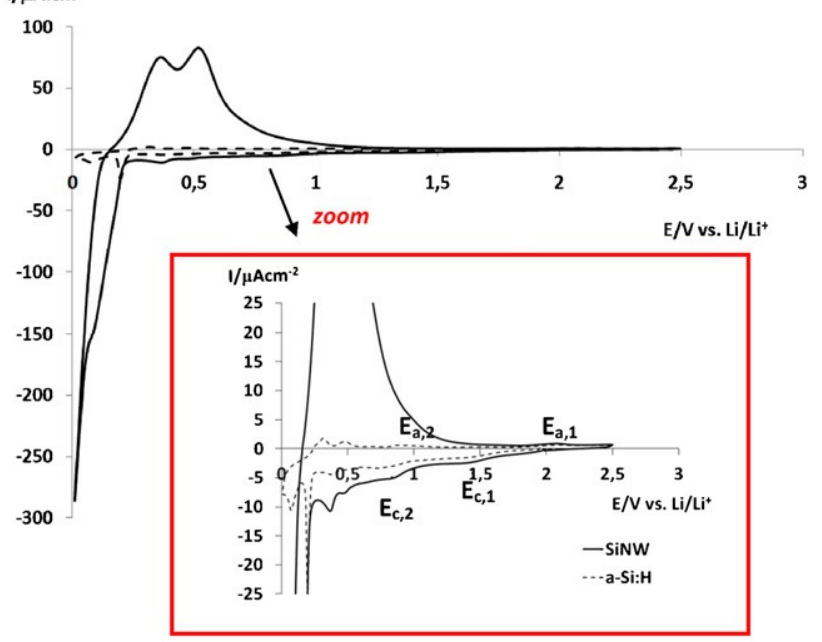

(c) $1 / \mu \mathrm{A} \cdot \mathrm{cm}^{-2}$

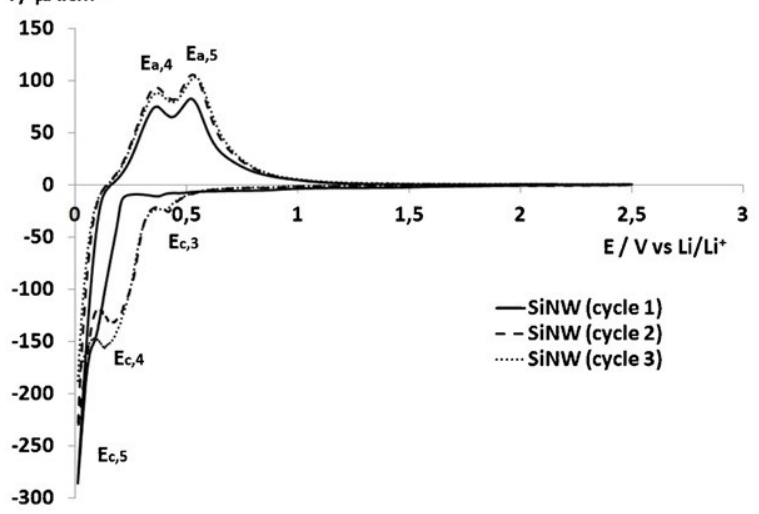

Fig. 1. Cyclic voltamperogram in $\mathrm{PC}^{2} \mathrm{LiClO}_{4}(1 \mathrm{M})$ at $20 / \mathrm{LV} \mathrm{s}^{-1}$ on (a) a thin amorphous film of a-Si:H and stainless steel substrate; (b) Si nanowires (SiNW) and a thin amorphous film of a-Si:H; (c) three first cycles (CV) on Si nanowires (SiNW). of stainless steel and a-Si:H thin film electrode (Fig. 1a) shows two broad cathodic peaks $E_{c, 1}$ and $E_{c, 2}$ at 1.45 and $0.75 \mathrm{~V}$, respectively. One small $\mathrm{E}_{\mathrm{c}, 3}$ peak at around $0.45 \mathrm{~V}$ (not discussed) and two sharp and intense peaks located at 0.2 and $0.1 \mathrm{~V}\left(\mathrm{E}_{\mathrm{c}, 4}\right.$ and $\mathrm{E}_{\mathrm{c}, 5}$, respectively) are only observed on a-Si:H films. The first cathodic peak $\left(E_{c, 1}\right)$ can be attributed to small-scale reduction of electrolyte and/or surface contaminations (including silicon oxide) on Si electrodes [25]. A reduction of trace of water $(30 \mathrm{ppm})$ present in the electrolyte cannot be completely excluded as already discussed in previous studies on $\mathrm{PC} / \mathrm{Li}$ salts electrochemical reduction performed on noble metals [30-32]. $E_{c, 2}$ peak present at $0.75 \mathrm{~V}$ is a principal peak attributed to reduction of the electrolyte on $\mathrm{Si}$ electrodes $[11,12,24-26]$. The very sharp $E_{c, 4}$ and the $E_{c, 5}$ peaks may correspond to the lithiation of amorphous Si, which have been reported to occur below $200 \mathrm{mV}$ [13,33]. Two features were observed during lithiation of amorphous $\mathrm{Si}$. It can be concluded that $E_{c, 5}$ and $E_{c, 4}$ peaks are related to formation of amorphous $\mathrm{Li}-\mathrm{Si}$ phase, since they are not observed on the CV performed on stainless steel. The $E_{c, 5}$ value has been observed in both crystallised and amorphous $\mathrm{Si}$ [35]. During the Li-Si de-alloying reactions, two anodic peaks $\left(E_{a, 5}\right.$ and $E_{a, 4}$, respectively, Fig. 1a) are observed at 0.36 and $0.52 \mathrm{~V}$, as it was reported in the literature for amorphous $\mathrm{Si}$ and thin Si films [34,35]. These two anodic peaks seem to correspond to de-alloying of amorphous $\mathrm{Li}-\mathrm{Si}$ phase as they are not present on the CV performed on the stainless steel substrate. These peaks are characteristic of the lithiation of amorphous $\mathrm{Si}$ and thin Si films [36-38]. The sharp nature of $E_{c, 4}$ peak is rather surprising, indicating a possibility of other processes related to the presence of $\mathrm{H}$-atoms in a-Si:H film. The small and broad anodic peaks, $\mathrm{E}_{\mathrm{a}, 2}$ and $\mathrm{E}_{\mathrm{a}, 1}$ located at 0.93 and $2.00 \mathrm{~V}$ are related to oxidation reaction of compounds reduced at cathodic process (peaks $E_{c, 1}$ and $E_{c, 2}$, Fig. 1a) on both stainless steel and a-Si:H thin film. Fig. 1b shows cyclic voltammetry performed on the SiNW electrode in $\mathrm{PC} / \mathrm{LiClO}_{4} 1 \mathrm{M}$. The same cathodic peaks $\left(\mathrm{E}_{\mathrm{c}, 1}, \mathrm{E}_{\mathrm{c}, 2}, \mathrm{E}_{\mathrm{c}, 3}\right.$ and $\left.\mathrm{E}_{\mathrm{c}, 4}\right)$ corresponding to the same electrochemical reactions occurring on a-Si:H electrodes (Fig. 1a) are observed for SiNW (Fig. 1b). The $E_{c, 1}, E_{c, 2}$ and $E_{c, 3}$ peaks related to electrochemical reactions occurring on the electrode surface are almost undetectable on the CV performed on the SiNW electrode. It can be noticed that in a case of the $\mathrm{CV}$ performed on the SiNW electrode the peak $E_{c, 4}$ (very well visible on the a$\mathrm{Si}: \mathrm{H}$ electrode, Fig. 1a) appears as a shoulder before the peak $E_{c, 5}$ (Fig. 1b). The peak $E_{c, 4}$ is attributed to lithiation of a small amount of amorphous Si present in crystalline SiNW, while the peak $E_{c, 5}$ $(<100 \mathrm{mV})$ is mainly attributed to lithiation of crystalline Si (present in SiNW), formation of amorphous $\mathrm{Li}-\mathrm{Si}$ phase (a-Li $\mathrm{i}_{\mathrm{X}} \mathrm{Si}$ ) and/or crystallisation to $\mathrm{Li}_{15} \mathrm{Si}_{4}$ phase at potentials lower than $50 \mathrm{mV}[7,34]$. De-alloying of amorphous $\mathrm{Li}-\mathrm{Si}$ phase occurs during the reverse cycle at the same potentials $\left(E_{a, 5}\right.$ and $E_{a, 4}$ in Fig. 1b) as for a-Si:H $\left(E_{a, 5}\right.$ and $E_{a, 4}$ in Fig. 1a). The two de-alloying peaks clearly seem to suggest that there is no crystallisation of a- $\mathrm{Li}_{\mathrm{X}} \mathrm{Si}$ onto $\mathrm{Li}_{15} \mathrm{Si}_{4}$ (c$\left.\mathrm{Li}_{15} \mathrm{Si}_{4}\right)$. These results are consistent with previous findings and can be related to nano-sized morphology of SiNW [39]. If c- $\mathrm{Li}_{15} \mathrm{Si}_{4}$ was formed a single de-lithiation peak characteristic of a twophase region (c- $\mathrm{Li}_{15} \mathrm{Si}_{4}$ and a-Si) should be observed [34]. In a case of CV performed on SiNW the peaks $E_{a, 5}$ and $E_{a, 4}$ are characterised by high current density (high charge) due to high specific area of SiNW electrode. The analysis of second and third cycles (Fig. 1c) clearly shows an intensity increase of the $E_{4, c}$ peak and a decrease of the $E_{c, 5}$ peak with cycling. The $E_{c, 4}$ peak displaces to much higher potentials indicating that the lithiation of amorphous $\mathrm{Si}$ is easier than lithiation of crystalline Si. These findings are in agreement with conversion of crystalline Si to amorphous Si during lithiation process [34]. Recent NMR studies have demonstrated that during the first lithiation the Si matrix breaks down to form amorphous Si matrix which can be lithiated at lower overpotentials [40]. 


\subsection{Morphological characterisation}

Fig. 2a and b show SEM micrographs of a-Si:H film before and after cycling (1CV). Before cycling, the a-Si:H film exhibits a pearlbead structure, whereas after one complete cycle in $\mathrm{PC} / \mathrm{LiClO}_{4} 1 \mathrm{M}$, it is covered by a thin, relatively homogenous and smooth-like film, which may indicate the presence of a SEI layer. Fig. 2c and d represent FEG-SEM micrographs of SiNW electrode before and after one cycle (CV). On the pristine SiNW electrode, nanowires appear regular-in-shape, whereas on the cycled SiNW electrode the nanowires are considerably thicker and covered with the SEI layer. The formation of the SEI layer all along each silicon nanowire confirms the good electrolyte diffusion in depth of the porous SiNW electrode. A significant modification of the a-Si:H and SiNW electrode related principally to full surface coverage by the SEI layer is confirmed by the electrochemical results as well as the XPS and ToF-SIMS analyses (vide infra).

\subsection{XPS characterisation of pristine and (de)lithiated silicon} electrodes

Fig. 3 presents the XP spectra of $\mathrm{C} 1 \mathrm{~s}$, O 1s and Si 2p core levels recorded for the pristine (a) and the cycled (1CV) a-Si:H and SiNW electrodes in $\mathrm{PC} / \mathrm{LiClO}_{4} 1 \mathrm{M}$ (b) and in EC:DMC (1:1)/LiPF 6 $1 \mathrm{M}$ (c). Fig. 4 shows the Li 1s, F 1s and $\mathrm{Cl} 2 \mathrm{p}$ core level spectra of a-Si:H and SiNW samples cycled in PC- (Fig. 4a) and EC:DMC-based electrolytes (Fig. 4b). The XP spectra for pristine a-Si:H and SiNW electrodes were corrected by $-1.2 \mathrm{eV}$ and $-1.0 \mathrm{eV}$, respectively, with respect to $\mathrm{C} 1 \mathrm{~s}$ reference $(285.0 \mathrm{eV})$.

Fig. 3a displays Si 2 $\mathrm{p}_{3 / 2}\left(\mathrm{E}_{\mathrm{B}}=99.3 \mathrm{eV}, \mathrm{FWHM}=0.7 \mathrm{eV}\right)$ and $\mathrm{Si} 2 \mathrm{p}_{1 / 2}$ $\left(\mathrm{E}_{\mathrm{B}}=98.7 \mathrm{eV}, \mathrm{FWHM}=0.7 \mathrm{eV}\right)$ spin orbit doublet assigned to silicon $\left(\mathrm{Si}^{0}\right)$ and non-deconvoluted Si 2p $\left(\mathrm{E}_{\mathrm{B}}=102.6 \mathrm{eV}, \mathrm{FWHM}=1.7 \mathrm{eV}\right)$ attributed to the native silicon oxide $\left(\mathrm{SiO}_{2}\right)$. The pristine SiNWs (Fig. 3a, Table 3) shows, similarly to the a-Si:H film, a Si $2 \mathrm{p}_{3 / 2}$ doublet and a non-deconvoluted $\mathrm{Si} 2 \mathrm{p}$ at higher binding energy attributed to $\mathrm{Si}^{0}$ and $\mathrm{SiO}_{2}$, respectively. The slightly larger FWHM values of $\mathrm{Si} 2 \mathrm{p}$ peaks for $\mathrm{SiNW}$ electrode $\left(\mathrm{FWHM}=0.9\right.$ for $\mathrm{Si}^{0}$ and $\mathrm{FWHM}=2.2 \mathrm{eV}$ for $\mathrm{SiO}_{2}$ ) can be related to different surface morphology (i.e. increased roughness of Si wire-like structure). The thickness of the native $\mathrm{SiO}_{2}$ formed on the SiNW calculated from Eq. (1) is around $1 \mathrm{~nm}$. However, this value can be only an approximate estimation, since Eq. (1) is only valid for planar surfaces. Moreover, Si $2 \mathrm{p}\left(\mathrm{Si}^{0}\right) / \mathrm{Si} 2 \mathrm{p}\left(\mathrm{SiO}_{\mathrm{x}}\right)$ intensity ratio was estimated to be equal to 5.7 and 1.7 for a-Si:H thin film and SiNW electrodes, respectively (Fig. 3a), indicating that the surface of SiNW electrode is more oxidised, which can be due to high surface area of SiNW. O 1s peak displayed at $\mathrm{E}_{\mathrm{B}}=532.3 \mathrm{eV}(\mathrm{FWHM}=1.7 \mathrm{eV})$ for a-Si:H thin films and at $\mathrm{E}_{\mathrm{B}}=532.6 \mathrm{eV}(\mathrm{FWHM}=1.7 \mathrm{eV})$ for SiNW samples (Fig. 3a) confirms the presence of a native $\mathrm{SiO}_{2}$ on the electrode surface. The oxygen to silicon intensity peaks ratios $\left(\mathrm{O} 1 \mathrm{~s}\left(\mathrm{SiO}_{\mathrm{x}}\right) / \mathrm{Si} 2 \mathrm{p}\left(\mathrm{SiO}_{\mathrm{x}}\right)\right)$ are 1.75 and 2.96 for SiNW and a-Si:H pristine samples, respectively. The slightly higher $\mathrm{O} 1 \mathrm{~s} / \mathrm{Si} 2 \mathrm{p}$ atomic intensity ratio found in a$\mathrm{Si}-\mathrm{H}$ with respect to the theoretical value $\left(\left[\begin{array}{lll}\mathrm{O} & 1 \mathrm{~s} / \mathrm{Si} 2 \mathrm{p}\end{array}\right]_{\mathrm{th}}=2\right)$, can be related to presence of oxygenated carbon species (contamination including $\mathrm{C}-\mathrm{O}$ or $\mathrm{O}=\mathrm{G}-\mathrm{O}$ bonds). Indeed, the presence of $\mathrm{SiO}_{2}$, $\mathrm{C}-\mathrm{O}$ and/or $\mathrm{O}=\mathrm{G}-\mathrm{O}$ in a-Si:H films is confirmed by the $\mathrm{O}: \mathrm{Si}: \mathrm{C}$ ratio, which was found to be equal to 5:2:1 if all oxygenated species, i.e., oxygenated carbon and silicon oxide, were taken into account. In this case a O:Si ratio equal to 2 is calculated.

After a complete CV in PC- and EC:DMC-based electrolytes performed on both electrodes (a-Si:H thin film and SiNW) the XP spectra show strong attenuation and positive shift of Si $2 p$ peaks (Fig. $3 b$ and c). The displacement of Si 2p peak to higher binding energy (of around $2 \mathrm{eV}$ ) for the a-Si:H thin films, indicates strong modification of the electrode surface due to formation of the SEI layer which contributes to charging effect. The attenuation of the
Si $2 p$ peaks is consistent with the growth of a SEI layer on the electrode surface. After correction of binding energies (BEs) of all spectra with reference to $C 1$ s peak $(285.0 \mathrm{eV})$, the Si $2 p$ peaks are found at $\mathrm{E}_{\mathrm{B}}=98.6 \mathrm{eV}$ and $98.1 \mathrm{eV}$ on the a-Si:H electrode cycled in PC and in EC:DMC-based electrolytes, respectively. The Si 2p signals (corresponding to $\mathrm{Si}^{0}$ and $\mathrm{SiO}_{2}$ ) are shifted to much lower $\mathrm{BE}$ values when comparing to pristine samples. The overcorrection of BEs of Si 2p core level peaks indicates that using the reference $C$ s peak (at $285.0 \mathrm{eV}$ ) to adjust the values of binding energies is not appropriate for all core level peaks. A discrepancy of binding energies of different components (core level peaks) can be influenced by different depth distribution of these components in analysed layer (SEI, $\mathrm{SiO}_{2}$ and/or Si layers). The correction of XP spectra with respect to Si $2 p(99.3 \mathrm{eV})$ reference shifts the Si $2 p$ peaks (corresponding to $\mathrm{SiO}_{2}$ ) back again to their expected values as observed on the pristine sample $\left(\mathrm{E}_{\mathrm{B}}=102.4\right.$ and $\mathrm{E}_{\mathrm{B}}=102.9 \mathrm{eV}$ in PC- and EC:DMC-based electrolytes, respectively, Table 2). The same findings are observed on SiNWs cycled in PC- (Fig. 3b) and EC:DMC-based electrolytes (Fig. 3c) where correction of $-2.3 \mathrm{eV}$ and $-2.1 \mathrm{eV}$, respectively, with respect to $C 1$ s reference (at $E_{B}=285.0 \mathrm{eV}$ ) leads to displacement of Si $2 p$ peaks to much lower BEs (see Table 2).

Moreover for SiNW electrode cycled in PC compared to EC:DMCbased electrolytes show much stronger attenuation of the Si 2p peaks and higher charge effect indicating that a thicker SEI layer is formed (as discussed above). The XP spectra calibration with reference to Si 2p (at $E_{B}=99.3 \mathrm{eV}$ ) leads to displacement of $C$ s and $O$ is peak energies to much higher values, when calibration is done with C 1s reference (Table 2). However, the calibration of the XP spectra with the reference to $\mathrm{Si} 2 \mathrm{p}(99.3 \mathrm{eV})$ does neither allow to obtain the right binding energies of the compounds of the SEI layer. Therefore, it is suggested that the organic-part of the SEI layer is likely present at the outermost surface. Li 1s and F 1s peak energy values are much closer to compounds found on SEI layer of cycled graphite in EC:DMC/LiPF $61 \mathrm{M}$ (Table 1), when Si 2p reference is used for BEs correction (Table 2 ).

While, on pristine samples the $\mathrm{C} 1 \mathrm{~s}$ and the $\mathrm{O}$ 1s core level peaks are mostly attributed to traces of organic contaminations and native $\mathrm{SiO}_{2}$ on the electrode surface, after cycling the significant increase of the $\mathrm{C} 1 \mathrm{~s}$ and $\mathrm{O}$ 1s peak intensities and the modifications produced on the peak shapes indicate the presence of the SEI layer (Fig. $3 b$ and c). If $\mathrm{C} 1 \mathrm{~s}(285.0 \mathrm{eV})$ reference is used the $\mathrm{C}$ 1s core level can be decomposed in four components at 285.0, 286.8, 288.7 and $290.0 \mathrm{eV}$ assigned to $-\mathrm{CH}_{2}-\mathrm{CH}_{2}, \mathrm{G}, \mathrm{O}, \mathrm{G} \mathrm{O}$ and $-\mathrm{CO}_{3}$ bonds, respectively, in the case of a-Si:H thin films cycled in PC-based electrolyte (Fig. 3b). Similar values (peaks at 285.0, 287.0, 288.8 and $290.1 \mathrm{eV}$ ) are found when the a-Si:H electrode is cycled in EC:DMC-based electrolyte (Fig. 3c using $C$ 1s reference). The new peak at $290.0 \mathrm{eV}$, assigned to carbon bonded to three oxygen atoms, is typical of carbonate-like species: $\mathrm{Li}_{2} \mathrm{CO}_{3}$ (from $\mathrm{DMC}$ reduction), alkyl carbonates $\left(\mathrm{ROCO}_{2} \mathrm{Li}\right.$ with $\mathrm{CH}_{3}, \mathrm{C}_{2} \mathrm{H}_{5}$ or $\mathrm{C}_{3} \mathrm{H}_{7}$ arising from the electrochemical reduction of DMC, EC or PC) or semicarbonate species $\left(\mathrm{R}(\mathrm{OCO} 2)_{2} \mathrm{Li}_{2}\right.$ with $\left(\mathrm{CH}_{2}\right)_{2}$ or $\mathrm{CH}_{3}\left(\mathrm{CH}_{2}\right)_{2}$ originating from the electrochemical reduction of EC or PC) [41-45]. The inorganic $\mathrm{Li}_{2} \mathrm{CO}_{3}$ and the organic $\mathrm{ROCO}_{2} \mathrm{Li}$ and $\mathrm{R}\left(\mathrm{OCO}_{2}\right) \mathrm{Li}_{2}$ species can be distinguished by their $\in \mathrm{O}$ bonding as the former contains a $\mathrm{C}$ atom attached to three $\mathrm{O}$ atoms, while the later has an additional $\mathrm{R}(\mathrm{C})-\mathrm{O}$ bond besides the carbon bonded to the three $\mathrm{O}$ atoms [41]. The $-\mathrm{CO}_{3}$ peak is more intense for both electrodes (a-Si:H and SiNW) when the electrodes are cycled in PC- rather than EC:DMC-based electrolytes. The more intense $\mathrm{C} 1 \mathrm{~s}$ peaks at 286.8/287.0 eV, assigned to $\mathrm{C}$ atom bonded to one $\mathrm{O}$ atom indicates the presence of lithium alkyl carbonates species $\left(\mathrm{ROCO}_{2} \mathrm{Li}\right)$. The $\mathrm{Li}_{2} \mathrm{CO}_{3}$ and $\mathrm{ROCO}_{2} \mathrm{Li}$ compounds can be distinguished by precise analysis of $\mathrm{O} 1 \mathrm{~s}$ spectra, where in the presence of $\mathrm{ROCO}_{2} \mathrm{Li}$ species the $\mathrm{O} 1 \mathrm{~s}$ is slightly asymmetric [41]. For the a-Si:H electrode cycled in PC-based electrolyte, the $\mathrm{O}$ 1s core level spectrum corrected with 

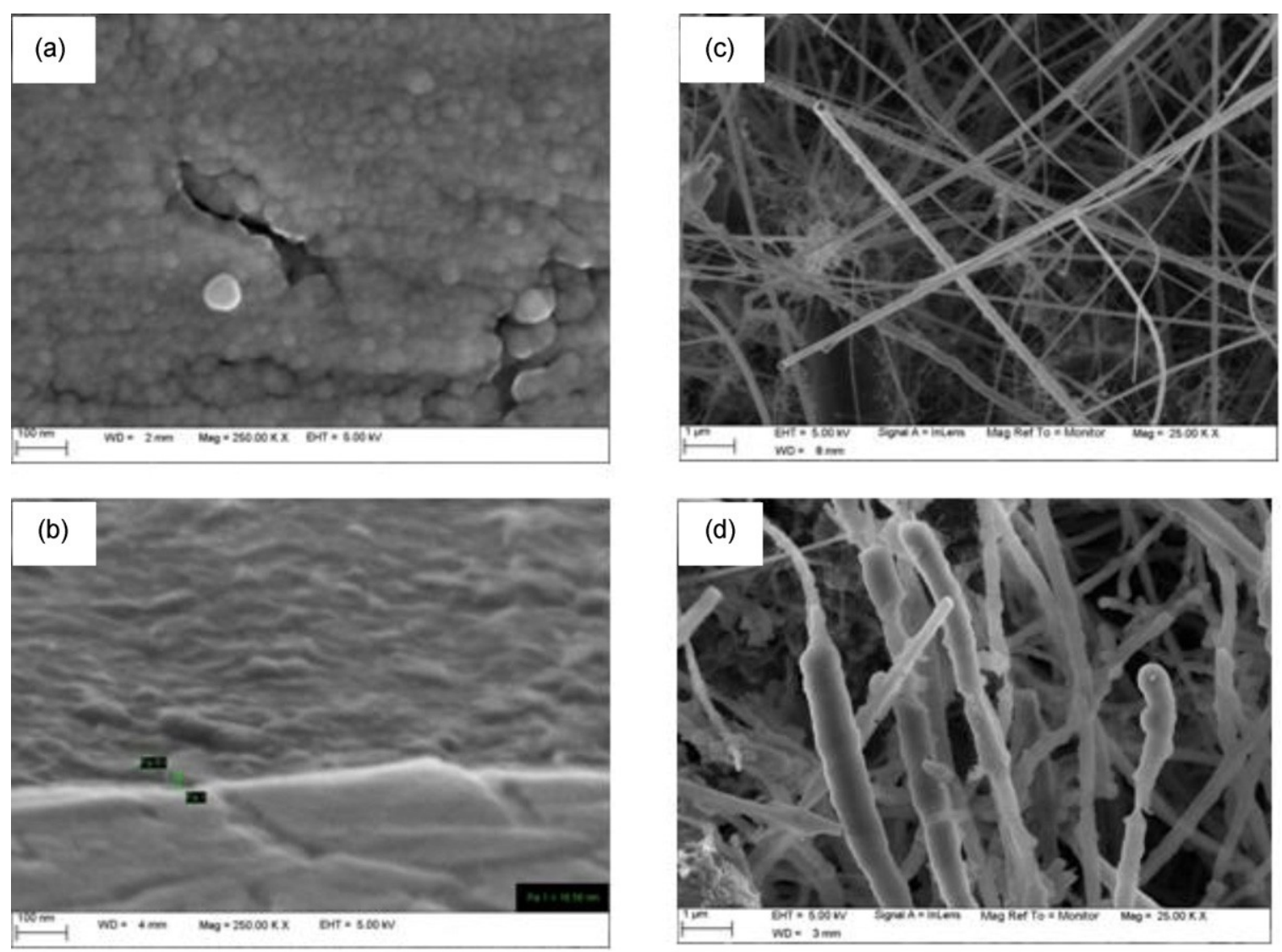

Fig. 2. FEG-SEM micrographs of (a) pristine thin film a-Si:H and (c) pristine Si nanowires (SiNW) and after one $\mathrm{CV}$ in $\mathrm{PC} / \mathrm{LiClO}_{4} 1 \mathrm{M}$ performed on (b) a-Si:H thin film and (d) SiNW.

\section{Table 1}

XPS peak assignments of SEI layer compounds according to the literature.

\begin{tabular}{|c|c|c|c|c|c|c|}
\hline Compound & Si 2p (eV) & C 1s (eV) & $\mathrm{O} 1 \mathrm{~s}(\mathrm{eV})$ & Li 1s (eV) & $\mathrm{Cl} 2 \mathrm{p}(\mathrm{eV})$ & F 1s (eV) \\
\hline $\begin{array}{l}\mathrm{SiO}_{2} \\
\mathrm{Si}^{0}\end{array}$ & $\begin{array}{l}103.3^{c} \\
99.3^{c}\end{array}$ & & & & & \\
\hline Hydrocarbons & & $\begin{array}{l}285 \\
284.8^{\mathrm{e}}\end{array}$ & & & & \\
\hline Polymer & & $285.5-286.5$ & & & & \\
\hline $\mathrm{PEO}(\mathrm{C}-\mathrm{O})$ & & $286.5^{\mathrm{d}, \mathrm{e}}$ & $533^{e}$ & & & \\
\hline $\mathrm{Li}_{2} \mathrm{CO}_{3}$ & & $291.5^{\mathrm{b}, \mathrm{e}}$ & $533.5-534^{\mathrm{b}, \mathrm{e}}$ & $56.5^{\mathrm{b}}$ & & \\
\hline & & $\begin{array}{l}290.1^{\mathrm{a}} \\
290.0^{\mathrm{c}, \mathrm{d}}\end{array}$ & $531.8^{\mathrm{a}}$ & $\begin{array}{l}55.5^{\mathrm{a}} \\
55.2^{\mathrm{c}}\end{array}$ & & \\
\hline $\mathrm{R}-\mathrm{CH}_{2} \mathrm{OCO}_{2} \mathrm{Li}$ & & $290.1^{\mathrm{a}}$ & $\begin{array}{l}531.8^{\mathrm{a}} \\
5322^{\mathrm{e}}\end{array}$ & & & \\
\hline $\mathrm{R}-\mathrm{CH}_{2} \mathrm{OCO}_{2} \mathrm{Li}$ & & $\begin{array}{l}286.5^{\mathrm{a}} \\
288.0^{\mathrm{d}} \\
287.5-288^{\mathrm{e}}\end{array}$ & $533.3^{\mathrm{a}}$ & $55.5^{\mathrm{a}}$ & & \\
\hline $\begin{array}{l}\mathrm{R}-\mathrm{CH}_{2} \mathrm{OCO}_{2} \mathrm{Li} \\
\mathrm{R}-\mathrm{CH}_{2} \mathrm{OLi}\end{array}$ & & $\begin{array}{l}285.3^{\mathrm{a}} \\
286.5^{\mathrm{d}}\end{array}$ & & & & \\
\hline $\mathrm{Li}-\mathrm{F}$ & & & & $\begin{array}{l}56.2-56.6^{\mathrm{b}, \mathrm{e}} \\
55.6^{\mathrm{c}}\end{array}$ & & $\begin{array}{l}686-686.5^{\mathrm{b}, \mathrm{e}} \\
685.5^{\mathrm{c}}\end{array}$ \\
\hline $\begin{array}{l}\mathrm{Li}-\mathrm{Cl} \\
\mathrm{Li}-\mathrm{ClO}_{4}\end{array}$ & & & & & $198.5^{\mathrm{g}}$ & \\
\hline $\mathrm{Li}-\mathrm{PF}_{6} / \mathrm{Lix}_{\mathrm{x}} \mathrm{PF}_{\mathrm{y}}$ & & & & $\begin{array}{l}57^{\mathrm{b}} \\
56.6^{\mathrm{c}}\end{array}$ & & $688^{\mathrm{b}, \mathrm{e}}$ \\
\hline $\mathrm{Li}-\mathrm{Si}$ & $\begin{array}{l}98^{\mathrm{d}} \\
98.4^{\mathrm{c}}\end{array}$ & & & & & \\
\hline $\begin{array}{l}\mathrm{Li}-\mathrm{OH} \\
\mathrm{Li}_{2} \mathrm{O}\end{array}$ & & & $\begin{array}{l}530^{f} \\
530^{f}\end{array}$ & & & \\
\hline
\end{tabular}

${ }^{a}$ Ref. [41] for $\mathrm{ROCO}_{2} \mathrm{Li}$ species calibrated to C $1 \mathrm{~s}(285.0 \mathrm{eV})$.

b Ref. [64] for SEI/graphite calibrated to C $1 \mathrm{~s}(284.4 \mathrm{eV}$ or $286.7 \mathrm{eV}$, in the presence of carbon black or not respectively).

c Ref. [19] for SEI/a-Si:H calibrated to C $1 \mathrm{~s}(285.0 \mathrm{eV})$.

d Ref. [11] for SEI/SiNW calibrated to C $1 \mathrm{~s}(284.5 \mathrm{eV})$.

e Ref. [48] for SEI/graphite calibrated to C 1s (284.3 eV).

${ }^{f}$ Ref. [65] for SEI/graphite calibrated to C $1 \mathrm{~s}(284.5 \mathrm{eV})$ of graphite or C $1 \mathrm{~s}$ (285.9eV) in the absence of graphite.

g Ref. [45,51]. 
a-Si:H thin films
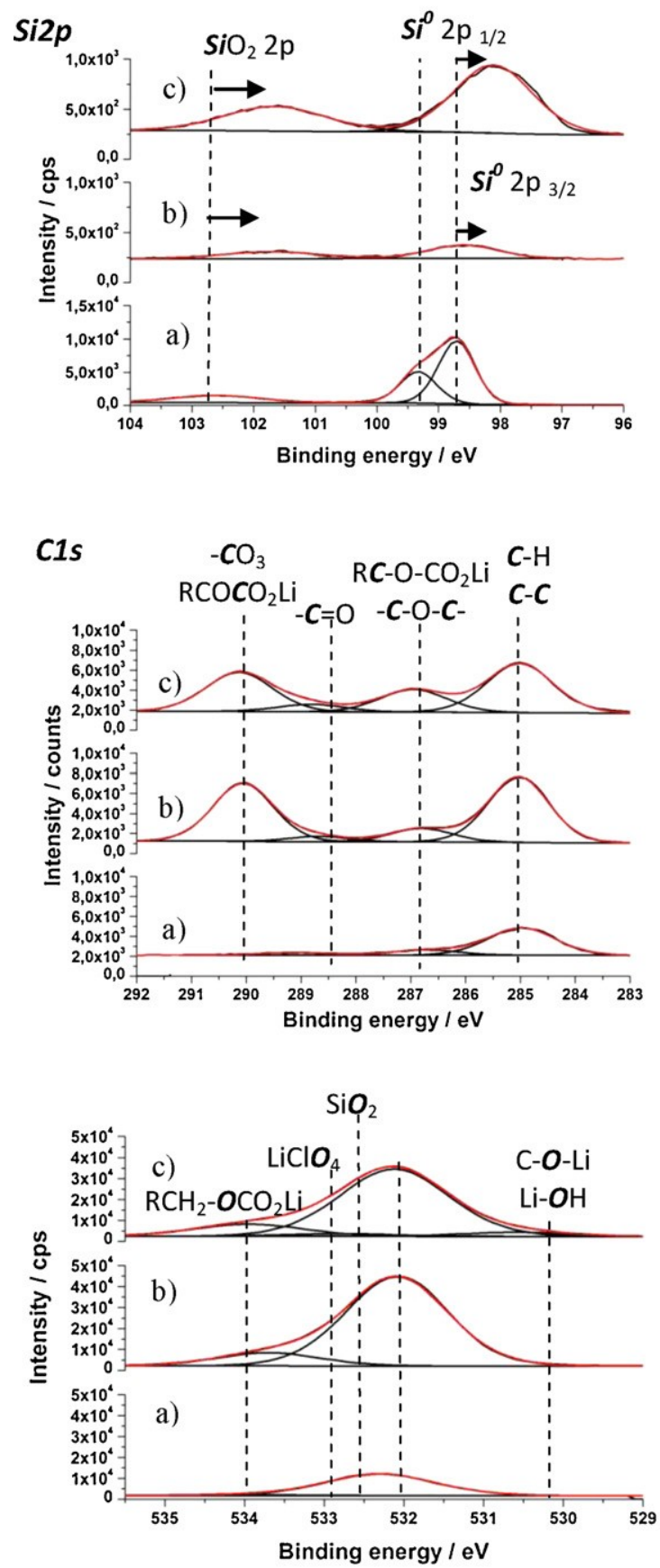

SiNW
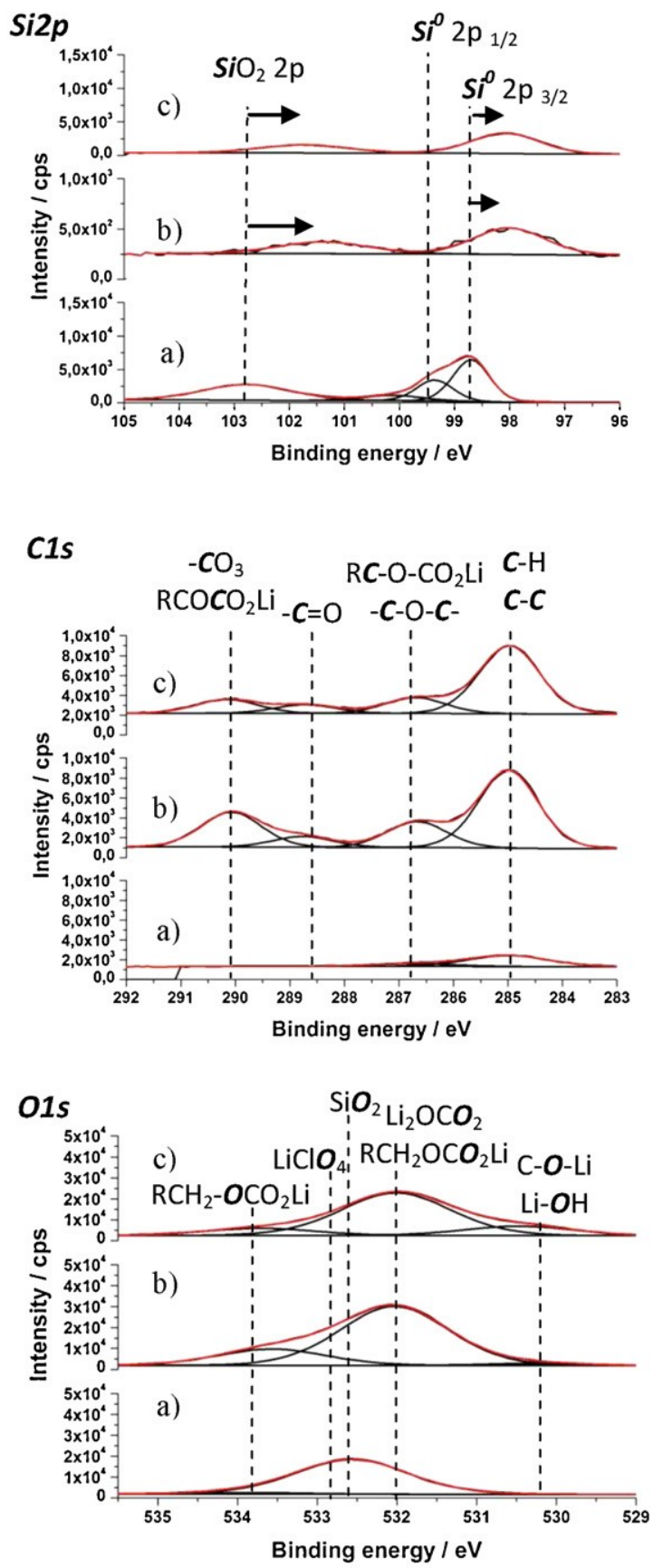

Fig. 3. XPS high resolution spectra of Si 2p, C 1s, O 1 s for (a) pristine a-Si:H thin film and SiNW and cycled (1CV) thin film a-Si:H and SiNW in (b) PC/LiClO 4 1M and (c) EC:DMC $(1: 1)(\mathrm{wt} / \mathrm{wt}) / \mathrm{LiPF}_{6} 1 \mathrm{M}$. The binding energies of all spectra were corrected with respect to $\mathrm{C} 1 \mathrm{~s}$ reference at $285.0 \mathrm{eV}$.

respect to C 1s reference can be decomposed into three major components located at 533.9, 532.0 and $530.1 \mathrm{eV}$ which can be assigned to alkyl chain $\left(\mathrm{RCH}_{2}-\right)$ bonded to an oxygen atom of a- $\mathrm{CO}_{3}$ group $\left[\mathrm{RCH}_{2}-\mathrm{O}-\mathrm{CO}_{2}\right.$ bond], $\mathrm{O}=\mathrm{G}-\mathrm{O}$ bonds in $-\mathrm{CO}_{3}$ and to $-\mathrm{OH}$ or $-\mathrm{OR}$, respectively [44,46-50]. No significant changes are observed in $\mathrm{O} 1 \mathrm{~s}$ peaks binding energies for the a-Si:H electrode cycled in EC:DMCbased electrolyte (Table 2). The O 1s spectrum for the SiNW samples cycled in PC-based electrolyte shows also three major components at $533.6,532.0$ and $530.3 \mathrm{eV}$. When replacing the electrolyte by EC:DMC, only small changes in the values of binding energies are observed, similarly to a-Si:H sample (Table 2). The peak around
$532.0 \mathrm{eV}$ is assigned to $\mathrm{O}=\mathrm{C}-\mathrm{O}$ bond in $-\mathrm{CO}_{3}$, which is related to the formation of $\mathrm{Li}_{2} \mathrm{CO}_{3}$ or alkyl carbonate species, in agreement with the increase of $\mathrm{C} 1 \mathrm{~s}$ peak intensity at $290.1 / 290.2 \mathrm{eV}$. The peak at $533.6 / 533.7 \mathrm{eV}$ is assigned to alkyl side chain $\left(\mathrm{RCH}_{2} \rightarrow\right)$ attached to $-\mathrm{CO}_{3}[41]$, in agreement with the $\mathrm{C} 1 \mathrm{~s}$ peak at $286.7 \mathrm{eV}$ attributed to $\mathrm{C}-\mathrm{O}$ bound found in $\mathrm{RCH}_{2} \mathrm{OCO}_{3}$ compounds (Table 1 ), while peak at 530.3 can be related to ROLi species originating from DMC reduction [25] or $\mathrm{LiOH}$ from trace water reduction [30,31] The SiNW samples cycled in EC:DMC- show a stronger $-\mathrm{OH} / \mathrm{RO}-$ contribution in the $\mathrm{O} 1 \mathrm{~s}$ core level peak than samples cycled in PCbased electrolyte. This can be related to formation of ROLi due to 


\section{a-Si:H thin films}

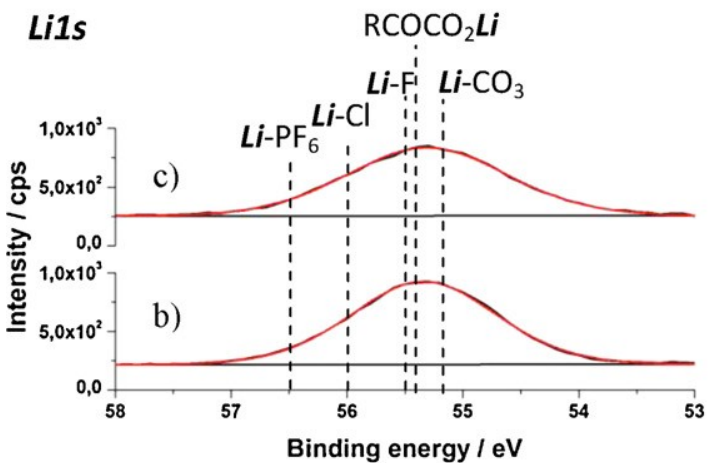

$C l 2 p$

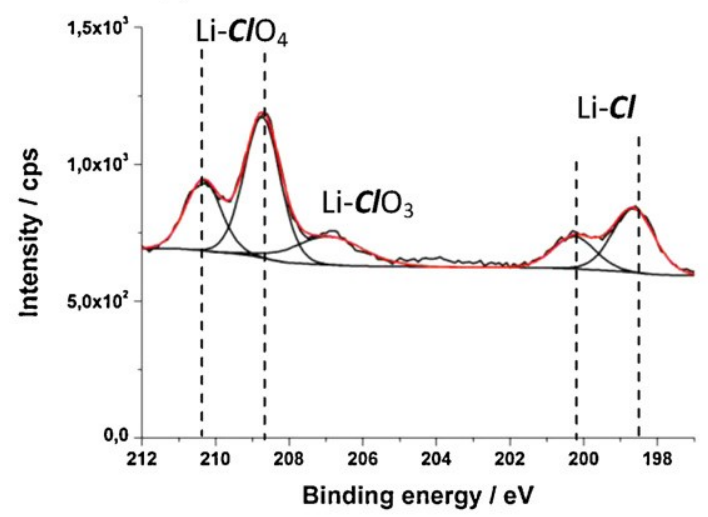

F1s

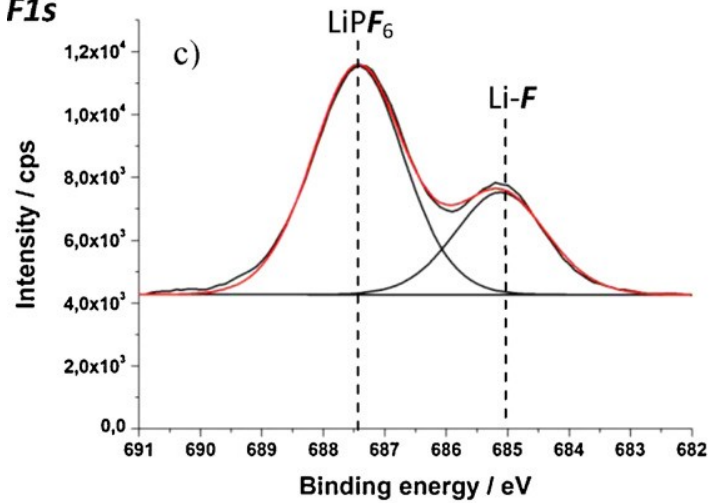

\section{SiNW}

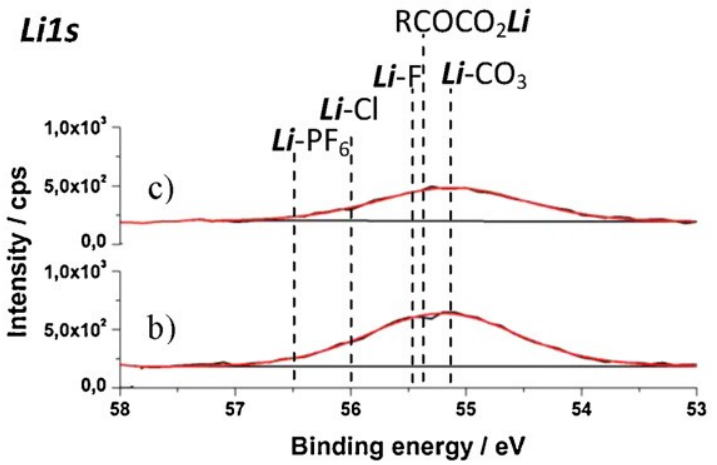

$C l 2 p$

b)
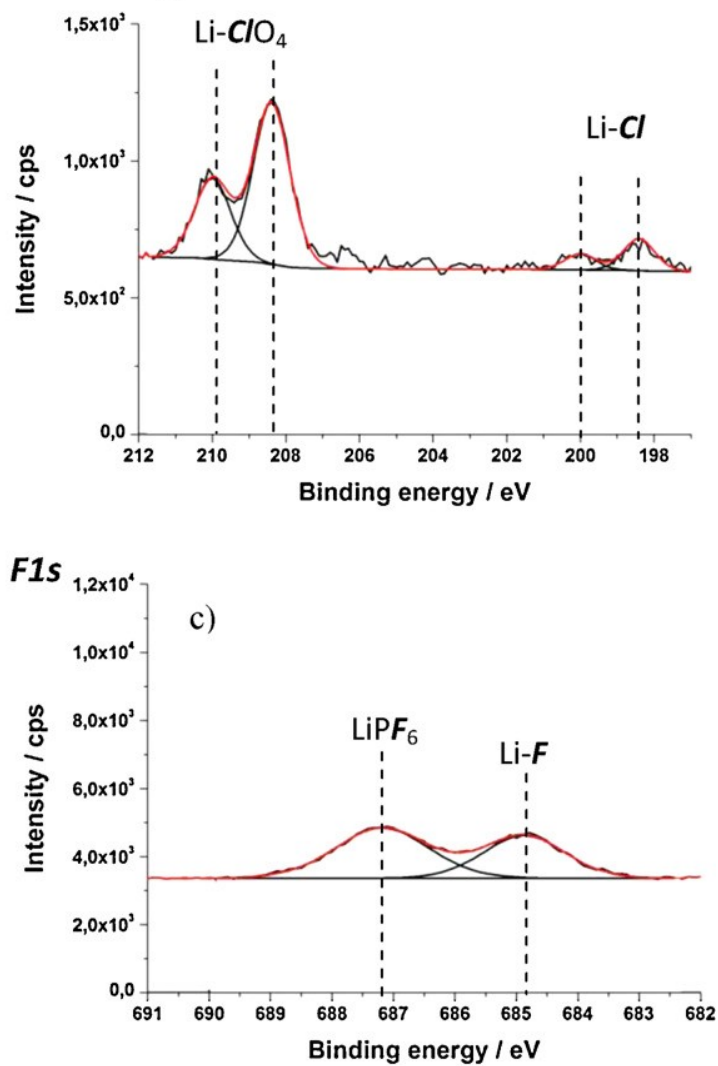

Fig. 4. XPS high resolution spectra of $\mathrm{Li} 1 \mathrm{~s}, \mathrm{Cl} 2 \mathrm{p}$ and $\mathrm{F} 1 \mathrm{~s}$ for (a) pristine a-Si:H thin film and $\mathrm{SiNW}$ and cycled (1CV) thin film a-Si:H and $\mathrm{SiNW}$ in (b) $\mathrm{PC} / \mathrm{LiClO} \mathrm{C}_{4} 1 \mathrm{M}$ and (c) EC:DMC (1:1) (wt/wt)/LiPF 6 1M. The binding energies of all spectra were corrected with respect to $\mathrm{C} 1 \mathrm{~s}$ reference at $285.0 \mathrm{eV}$.

reduction of DMC. The contribution of $-\mathrm{OH} / \mathrm{RO}-$ is not as significant as the contribution of alkyl carbonates and $\mathrm{Li}_{2} \mathrm{CO}_{3}$ in the composition of the SEI layer.

Salt decomposition (reduction) products were identified from Li 1s, F 1s and $\mathrm{Cl} 2 \mathrm{p}$ peak analysis (Fig. 4). Both a-Si:H and SiNW samples cycled in PC- (Fig. 4a) and EC:DMC-based(Fig. 4b) electrolytes have rather high lithium content ( $\sim 25 \%$ at.) after one complete cycle. As the $\mathrm{Li} 1 \mathrm{~s}$ peak is symmetrical and centred at $55.2 \mathrm{eV}$ (FWHM $\sim 1.6 \mathrm{eV}$ ), no attempt was made to assign precisely Li-containing species from $\mathrm{Li} 1$ s core level spectra deconvolution. The $\mathrm{Li} 1 \mathrm{~s}$ at binding energy of $55.2 \mathrm{eV}$ can be attributed to $\mathrm{Li}_{2} \mathrm{CO}_{3}$ and lithium alkyl carbonate species $\left(\mathrm{ROCO}_{2} \mathrm{Li}\right)$ [41,45]. For a$\mathrm{Si}: \mathrm{H}$ and SiNWs cycled in electrolytes containing $\mathrm{LiClO}_{4}$ salt, $\mathrm{LiCl}$
( $56 \mathrm{eV}$ ) is observed in the SEI layer as confirmed by the appearance of a $\mathrm{Cl} 2 \mathrm{p}_{3 / 2}$ and $\mathrm{Cl} 2 \mathrm{p}_{1 / 2}$ peaks at around 200.2/200.0 eV and 198.6/198.4 eV, respectively, while $\mathrm{LiClO}_{4}$ salt contamination was confirmed by $\mathrm{Cl} 2 \mathrm{p}_{3 / 2}$ and $\mathrm{Cl} 2 \mathrm{p}_{1 / 2}$ peaks appearing at 210.0 and $208.4 \mathrm{eV}$, respectively [51]. The assessment of the contribution of $\mathrm{LiClO}_{4}$ to the Li1s core level peak is difficult as no reference data can be found in the literature. For samples cycled in electrolytes containing the $\mathrm{LiPF}_{6}$ salts, the $\mathrm{Li} 1 \mathrm{~s}$ peak includes contributions from $\mathrm{LiF}$ (from 56.6 to $55.6 \mathrm{eV}$ ) and $\mathrm{LiPF}_{6}$ (or $\mathrm{Li}_{\mathrm{x}} \mathrm{PF}_{\mathrm{y}}$ species) (from 57 to $56.5 \mathrm{eV}$ ) [45] (Table 1) originating from salt reduction/decomposition reactions and salt contamination. The quantitative analysis of $\mathrm{F} 1 \mathrm{~s} / \mathrm{P} 2 \mathrm{p}$ ratio equal to 6 indicates the presence of $\mathrm{LiPF}_{6}$ compounds (Table 3). 
Table 2

Binding energies values for silicon samples cycled in $\mathrm{PC} / \mathrm{LiClO}_{4} 1 \mathrm{M}(\mathrm{PC})$ and $\mathrm{EC}: \mathrm{DMC}(1: 1) / \mathrm{LiPF}_{6} 1 \mathrm{M}$ with two different references for the charge correction (C 1s and Si 2p).

\begin{tabular}{|c|c|c|c|c|c|c|c|c|c|c|c|c|}
\hline Sample & C 1s (eV) & & $\mathrm{O} 1 \mathrm{~s}(\mathrm{eV})$ & & Si $2 \mathrm{p}(\mathrm{eV})$ & & Li 1s (eV) & & F 1s (eV) & & $\mathrm{Cl} 2 \mathrm{p}(\mathrm{eV})$ & \\
\hline \multirow{2}{*}{\multicolumn{13}{|c|}{$\begin{array}{l}\text { a-Si:H } \\
\text { Pristine }\end{array}$}} \\
\hline & \multicolumn{12}{|c|}{ Pristine } \\
\hline & 285 & & 531.3 & & 98.7 & & & & & & & \\
\hline & 286.7 & & 532.3 & & 99.3 & & & & & & & \\
\hline & 288.7 & & 533.9 & & 102.6 & & & & & & & \\
\hline & 289.6 & & & & & & & & & & & \\
\hline \multicolumn{13}{|l|}{ PC } \\
\hline & $285.0^{\mathrm{a}}$ & $285.7^{\mathrm{b}}$ & $533.9^{\mathrm{a}}$ & $534.7^{b}$ & $98.6^{\mathrm{a}}$ & $99.3^{b}$ & $55.2^{\mathrm{a}}$ & $56.0^{\mathrm{b}}$ & & & $210.0^{\mathrm{a}}$ & $211.0^{\mathrm{b}}$ \\
\hline & $286.8^{\mathrm{a}}$ & $287.5^{\mathrm{b}}$ & $532.0^{\mathrm{a}}$ & $532.8^{\mathrm{b}}$ & $101.6^{\mathrm{a}}$ & $102.4^{\mathrm{b}}$ & & & & & $208.4^{\mathrm{a}}$ & $209.4^{\mathrm{b}}$ \\
\hline & $288.7^{\mathrm{a}}$ & $289.4^{\mathrm{b}}$ & $530.1^{\mathrm{a}}$ & $530.9^{b}$ & & & & & & & $200.2^{\mathrm{a}}$ & $201.0^{\mathrm{b}}$ \\
\hline & $290.0^{\mathrm{a}}$ & $290.7^{\mathrm{b}}$ & & & & & & & & & $198.6^{\mathrm{a}}$ & $199.4^{\mathrm{b}}$ \\
\hline \multicolumn{13}{|l|}{ EC:DMC } \\
\hline & $285.0^{\mathrm{a}}$ & $286.2^{\mathrm{b}}$ & $533.9^{\mathrm{a}}$ & $535.1^{\mathrm{b}}$ & $98.1^{\mathrm{a}}$ & $99.3^{\mathrm{b}}$ & $55.3^{a}$ & $56.5^{\mathrm{b}}$ & $687.4^{\mathrm{a}}$ & $688.6^{\mathrm{b}}$ & & \\
\hline & $287.0^{\mathrm{a}}$ & $288.2^{\mathrm{b}}$ & $532.1^{\mathrm{a}}$ & $533.3^{\mathrm{b}}$ & $101.7^{\mathrm{a}}$ & $102.9^{\mathrm{b}}$ & & & $685.1^{\mathrm{a}}$ & $686.3^{\mathrm{b}}$ & & \\
\hline & $288.8^{\mathrm{a}}$ & $290.0^{\mathrm{b}}$ & $530.6^{\mathrm{a}}$ & $531.7^{\mathrm{b}}$ & & & & & & & & \\
\hline & $290.1^{\mathrm{a}}$ & $291.3^{\mathrm{b}}$ & & & & & & & & & & \\
\hline \multicolumn{13}{|l|}{ SiNW } \\
\hline \multicolumn{13}{|l|}{ Pristine } \\
\hline & 285 & & 533.9 & & 98.7 & & & & & & & \\
\hline & 286.7 & & 532.5 & & 99.5 & & & & & & & \\
\hline & & & & & 102.7 & & & & & & & \\
\hline \multicolumn{13}{|l|}{ PC } \\
\hline & $285.0^{\mathrm{a}}$ & $286.3^{\mathrm{b}}$ & $533.6^{\mathrm{a}}$ & $534.9^{b}$ & $98.0^{\mathrm{a}}$ & $99.3^{\mathrm{b}}$ & $55.2^{\mathrm{a}}$ & $56.5^{\mathrm{b}}$ & & & $210.0^{\mathrm{a}}$ & $211.3^{b}$ \\
\hline & $286.7^{\mathrm{a}}$ & $288.0^{\mathrm{b}}$ & $532.0^{\mathrm{a}}$ & $533.3^{b}$ & $101.4^{\mathrm{a}}$ & $102.7^{\mathrm{b}}$ & & & & & $208.4^{\mathrm{a}}$ & $209.7^{\mathrm{b}}$ \\
\hline & $288.8^{\mathrm{a}}$ & $290.1^{\mathrm{b}}$ & $530.3^{a}$ & $531.6^{\mathrm{b}}$ & & & & & & & $200.0^{\mathrm{a}}$ & $201.3^{b}$ \\
\hline & $290.1^{\mathrm{a}}$ & $291.4^{\mathrm{b}}$ & & & & & & & & & $198.4^{\mathrm{a}}$ & $199.7^{\mathrm{b}}$ \\
\hline \multicolumn{13}{|l|}{ EC:DMC } \\
\hline & $285.0^{\mathrm{a}}$ & $286.2^{\mathrm{b}}$ & $533.7^{\mathrm{a}}$ & $534.9^{b}$ & $98.1^{\mathrm{a}}$ & $99.3^{\mathrm{b}}$ & $55.1^{\mathrm{a}}$ & $56.3^{\mathrm{b}}$ & $687.2^{\mathrm{a}}$ & $688.4^{\mathrm{b}}$ & & \\
\hline & $286.7^{\mathrm{a}}$ & $287.9^{\mathrm{b}}$ & $532.0^{\mathrm{a}}$ & $533.2^{\mathrm{b}}$ & $101.7^{\mathrm{a}}$ & $102.9^{\mathrm{b}}$ & & & $684.9^{\mathrm{a}}$ & $687.1^{\mathrm{b}}$ & & \\
\hline & $288.7^{\mathrm{a}}$ & $289.9^{\mathrm{b}}$ & $530.5^{\mathrm{a}}$ & $531.7^{\mathrm{b}}$ & & & & & & & & \\
\hline & $290.2^{\mathrm{a}}$ & $291.2^{\mathrm{b}}$ & & & & & & & & & & \\
\hline
\end{tabular}

a C $1 \mathrm{~s}(285.0 \mathrm{eV})$

b Si $2 p(99.3 \mathrm{eV})$ charge effects correction.

Table 3

Surface composition (atomic percentage) for cycled a-Si:H thin film electrodes measured by XPS.

\begin{tabular}{llllllll}
\hline & $\mathrm{Si}$ & $\mathrm{C}$ & $\mathrm{O}$ & $\mathrm{Li}$ & $\mathrm{Cl}$ & $\mathrm{F}$ & $\mathrm{P}$ \\
\hline PC-based electrolyte & 2.2 & 30.0 & 47.4 & 19.8 & 0.6 & - & - \\
EC:DMC-based electrolyte & 4.1 & 25.6 & 35.7 & 25.2 & - & 6.8 & 9.4 \\
\hline
\end{tabular}

From the F 1s core level analysis, a peak at $687.4 / 687.2 \mathrm{eV}$ and at 685.1/684.9 eV corresponding to $\mathrm{LiPF}_{6}$ and LiF species [11], respectively, was found on the a-Si:H and SiNW cycled in EC:DMC-based electrolyte (Fig. 4a). The values of BEs of these two peaks are lower by about $0.5-1 \mathrm{eV}$ than the values reported in the literature for $\mathrm{LiF}$ (686-686.5 eV) and $\mathrm{LiPF}_{6}(688.0 \mathrm{eV})$ [52-54]. After charge correction made with reference to the $\mathrm{Si} 2 \mathrm{p}$ core level peak, the binding energies of $\mathrm{LiPF}_{6}$ and $\mathrm{LiF}$ are in agreement with those reported in the literature, e.g. $688.6 / 688.4$ and $686.3 / 687 \mathrm{eV}$, respectively (Table 2). The charge correction vs $\mathrm{Si} 2 \mathrm{p}$ shifts also the Li1s peak to $56.5 / 56.3 \mathrm{eV}$, which can be assigned to the presence of $\operatorname{LiF}[50,64]$.

Tables 3 and 4 show atomic percentage of the elements found in a-Si:H and SiNW samples, respectively, after one complete CV. Both Si electrode samples (a-Si:H and SiNWs) have higher content of C, $\mathrm{O}$ and Li species when cycled in PC- than in EC:DMC-based electrolytes. The atomic percentage values found for samples cycled in EC:DMC-based electrolytes are: C $\cong 26 \%$ and $30 \%, O=36 \%$ and $34 \%$,

Table 4

Surface composition (atomic percentage) of the SiNW electrodes measured by XPS.

\begin{tabular}{|c|c|c|c|c|c|c|c|}
\hline & $\mathrm{Si}$ & C & $\mathrm{O}$ & $\mathrm{Li}$ & $\mathrm{Cl}$ & $\mathrm{F}$ & $\mathrm{P}$ \\
\hline PC-based electrolyte & 1.4 & 36.1 & 39.0 & 22.6 & 1.0 & - & - \\
\hline EC:DMC-based electrolyte & 17.3 & 30.0 & 34.4 & 16.0 & - & 2.4 & \\
\hline
\end{tabular}

$\mathrm{Li}=25 \%$ and $16 \%$ for the a-Si:H thin film and the SiNWs, respectively. These values are close to the atomic percentages reported for Si cycled in EC:DMC-based electrolytes [20], where the SEI layer was suggested to be oxygen-rich in contrast to Si cycled in fluoro-ethylene carbonate (FEC)-based electrolytes [20]. The atomic percentage of oxygen in the SEI layer formed on the a$\mathrm{Si}: \mathrm{H}$ thin film and the SiNWs after cycling in PC-based electrolyte is higher that those obtained in EC-DMC electrolyte (Tables 3 and 4). As shown from the XPS depth profiles by Nakai et al. [20] the SEI layer grown on the Si film electrode cycled in EC-based electrolyte containing $\mathrm{LiPF}_{6}$ was thicker than those formed in FEC-based electrolytes containing $\mathrm{LiPF}_{6}$ salt, due to formation of fluoride ions from the solvent decomposition reactions in the latter case. Here, the growth of thicker SEI layer in the electrolyte free of fluorinated salts can be interpreted according to the same reasoning used for the mechanism of electrolyte reduction.

\subsection{ToF-SIMS depth profile analyses of pristine and (de)lithiated silicon electrodes}

ToF-SIMS ion-depth concentration profiles are collected from negative-ion mass spectra as a function of etching time. The intensity is reported using a logarithmic scale in order to magnify the low intensity signals. The variation of the ion intensity with sputtering time reflects the variation of the in-depth concentration of the analysed ions but also the influence of the chemical environment on ionisation/emission yield of analysed species (called matrix effect). To define $\mathrm{SiO}_{2}$, $\mathrm{Si}$, substrate (SS) and SEI regions, $75 \%$ of the maximum intensity of $\mathrm{SiO}_{2}{ }^{-}, \mathrm{Si}_{3}{ }^{-}, \mathrm{FeO}_{2}{ }^{-}$and $\mathrm{Li}^{-}$ion signals, respectively, was used as criterion. These regions are defined in ToF-SIMS figures (Figs. 5 and 6) with vertical dashed lines. However, the use of this criterion shows its limit in pristine (Fig. 5a) and 

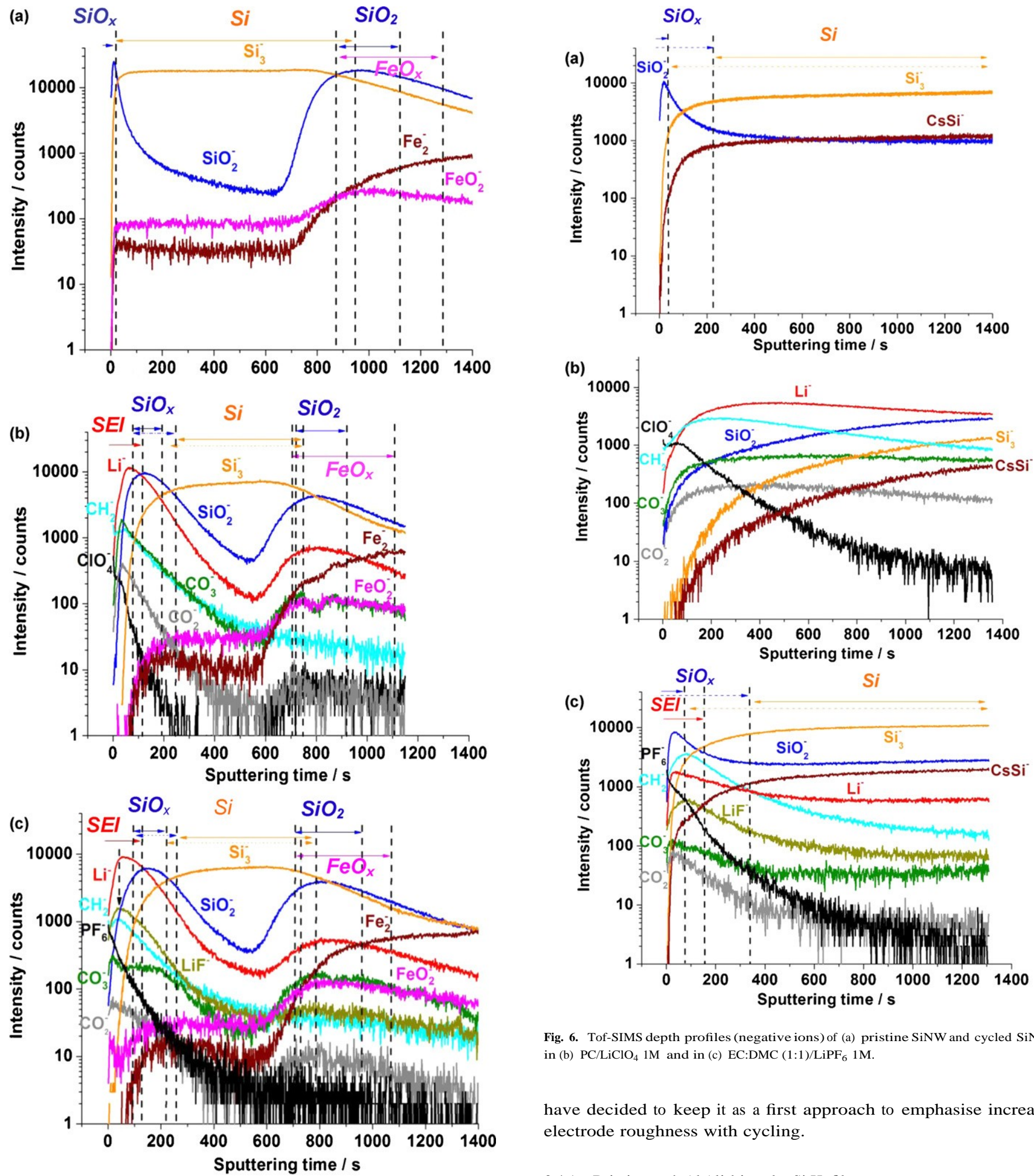

Fig. 6. Tof-SIMS depth profiles (negative ions) of (a) pristine SiNW and cycled SiNW in (b) $\mathrm{PC} / \mathrm{LiClO}_{4} 1 \mathrm{M}$ and in (c) EC:DMC (1:1)/ $\mathrm{LiPF}_{6} 1 \mathrm{M}$.

have decided to keep it as a first approach to emphasise increased electrode roughness with cycling.

3.4.1. Pristine and (de)lithiated a-Si:H films

Fig. 5a shows the ToF-SIMS ion depth profiles of $\mathrm{SiO}_{2}{ }^{-}$, $\mathrm{Si}_{3}{ }^{-}, \mathrm{Fe}_{2}{ }^{-}$and $\mathrm{FeO}_{2}{ }^{-}$performed on pristine a-Si:H thin film (30 nm in thickness) deposited on a stainless steel substrate. Depth profiles of ions constituting the SEI layer $\left(\mathrm{Li}^{-}, \mathrm{CH}_{2}{ }^{-}, \mathrm{CO}_{2}{ }^{-}, \mathrm{CO}_{3}{ }^{-}, \mathrm{ClO}_{4}{ }^{-}, \mathrm{LiF}^{-}\right.$and $\left.\mathrm{PF}_{6}{ }^{-}\right)$are also presented in Fig. $5 \mathrm{~b}$ and $5 \mathrm{c}$ for a-Si:H thin films cycled in PC- and in EC:DMCbased electrolytes, respectively. Several regions can be identified on the a-Si:H pristine electrode (Fig. 5a). The very first seconds of sputtering are characterised by a very sharp increase for all ion signals, which corresponds to the lapse of time needed to reach ion 
sputtering stationary state. In the first $\sim 20$ s of etching, the $\mathrm{SiO}_{2}{ }^{-}$ ion signal reaches its maximum marking the native silicon oxide region and then rapidly decreases at the maximum of $\mathrm{Si}_{3}{ }^{-}$ion signal. A stable $\mathrm{Si}_{3}{ }^{-}$signal is observed over $\sim 800 \mathrm{~s}$ marking a homogenous, thin $\mathrm{Si}$ layer. The $\mathrm{SiO}_{2}{ }^{-}$signal becomes again more intense at the $\mathrm{Si}$ thin film (given by $\mathrm{Si}_{3}{ }^{-}$)/stainless steel (given by $\mathrm{Fe}_{2}{ }^{-}$and $\mathrm{FeO}_{2}{ }^{-}$) interface, indicating the presence of $\mathrm{SiO}_{2}$. The $\mathrm{Fe}_{2}{ }^{-}$and $\mathrm{FeO}_{2}{ }^{-}$signals are also observed from $0 \mathrm{~s}$ to $700 \mathrm{~s}$ sputtering time but their intensity are rather low. The $\mathrm{Fe}_{2}{ }^{-}$and $\mathrm{FeO}_{2}{ }^{-}$ signals observed from the beginning of sputtering originate from imperfections (like defects and pinholes) present in the a-Si:H films prepared by PVD [55-57]. Through the pinholes the primary ions can easily reach the exposed substrate surface $\left(\mathrm{Fe}_{2}{ }^{-}\right.$and $\mathrm{FeO}_{2}{ }^{-}$signals). However after $700 \mathrm{~s}$ of sputtering, the $\mathrm{Fe}_{2}{ }^{-}$and $\mathrm{FeO}_{2}{ }^{-}$signals become more intense. The maximum intensity of the $\mathrm{Fe}_{2}{ }^{-}$ion profile is stabilised near $1200 \mathrm{~s}$, while that of $\mathrm{FeO}_{2}{ }^{-}$ion profile reaches a maximum near $950 \mathrm{~s}$ to thereafter slowly declines. Moreover, the $\mathrm{FeO}_{2}{ }^{-}$and the $\mathrm{SiO}_{2}{ }^{-}$ion profiles have similar behaviour at the silicon/substrate interface. These results indicate that during the first stages of a-Si:H deposition, silicon oxide is formed, due to reaction of oxygen atoms, coming from the native oxide of the stainless steel substrate, with the newly formed hydrogenated amorphous silicon layer. The pristine a-Si:H electrode is characterised by a homogenous thin layer of silicon metal and the presence of silicon and iron oxides at the $\mathrm{Si}$ /substrate interface. The growth of a spurious thermal oxide in the initial stages of the deposition process prior to complete sealing at the substrate surface can contribute to the interfacial oxides as previously observed at ALD layer/steel (or stainless steel) substrate interfaces [58-60].

Fig. 5b displays the depth profiles (negative ions) of a-Si:H after one complete CV (charge/discharge) in $\mathrm{PC}^{2} \mathrm{LiClO}_{4}(1 \mathrm{M})$ at $20 / \mathrm{LV} \mathrm{s}^{-1}$, where some modifications can be observed. The first modification concerns the slight decrease in the sputtering time from $700 \mathrm{~s}$ to $600 \mathrm{~s}$ necessary to reach the interface silicon/stainless steel substrate which can indicate a contraction of amorphous silicon film after delithiation and/or structural damages of the a-Si:H film. Significant modifications can be observed in the $\mathrm{Si}_{3}{ }^{-}$profile: displacement of the etching time from $0 \mathrm{~s}$ to $\sim 40 \mathrm{~s}$; marked decrease in the $\mathrm{Si}_{3}{ }^{-}$signal intensity (from 20,000 to 5000 counts); and reduction of the sputtering time length from nearly $\sim 800 \mathrm{~s}$ (before cycling) to $\sim 500 \mathrm{~s}$ (after cycling). Changes are also observed on the $\mathrm{SiO}_{2}$ - ion profile: decrease in the maximum signal intensity (from 20,000 to 9000 counts); and increase of the etching time length (from 20 s to $\sim 150-110$ s, given by dashed and solid arrows, respectively). The last modification concerns the appearance of new ions $\left(\mathrm{Li}^{-}, \mathrm{CH}_{2}{ }^{-}, \mathrm{CO}_{2}{ }^{-}, \mathrm{CO}_{3}{ }^{-}, \mathrm{ClO}_{4}{ }^{-}, \mathrm{LiF}^{-}\right.$and $\mathrm{PF}_{6}{ }^{-}$) in the depth profile (prior to the $\mathrm{Fe}_{2}-$ signal), which correspond to the presence of the SEI layer (ions corresponding to decomposition products of the electrolyte). The difference between the beginning of the sputtering time and the appearance of the $\mathrm{Fe}_{2}{ }^{-}$signal could be used to estimate the SEI layer thickness.

A small intensity shoulder is observed in the $\mathrm{Li}^{-}$ion profile before the maximum ion intensity is reached $(\sim 100 \mathrm{~s})$ and then the $\mathrm{Li}^{-}$declines to reach a minimum intensity near $\sim 600 \mathrm{~s}$. This two-step $\mathrm{Li}^{-}$profile can be related to lithium ions being ionised from two different chemical environments: organic vs inorganic matrix and/or non-oxide/oxide environments, also called matrices, which affects lithium ionisation/emission yields. This two-step $\mathrm{Li}^{-}$ profile behaviour was already observed (but not discussed) in the ToF-SIMS ion profiles of de-lithiated thin film $\mathrm{Cr}_{2} \mathrm{O}_{3} / \mathrm{Cr}$ electrodes [61]. This profile shape was not observed in de-lithiated tin alloys cycled in $\mathrm{PC} / \mathrm{LiClO}_{4} 1 \mathrm{M}$ (Sn-Co, Sn-Ni) [50,62]. Moreover, at the silicon/substrate interface the $\mathrm{Li}^{-}$signal intensity increases again and follows $\mathrm{SiO}_{2}{ }^{-}$signal intensity. This can be due to enhanced ionisation/emission of lithium ions in $\mathrm{SiO}_{2}$ (called matrix effect) or due to lithium trapped at the silicon/substrate interface. The irreversible trapping of the lithium ions at the active material electrode thin film/metallic substrate interface after cycling was already observed in our previous studies [63]. It was shown that the quantity of lithium accumulated at the electrode thin film/substrate interface depends on the number of cycles (lithium insertion/de-insertion) [63] and on electrode film/substrate cohesion. Lithium trapping had deleterious effect on cycling stability and capacity retention [50,62,63].

A very intense $\mathrm{ClO}_{4}{ }^{-}$signal is observed at the first seconds of etching time and then it rapidly declines just before the maximum intensity of $\mathrm{Li}^{-}$ion profile is reached, indicating that $\mathrm{ClO}_{4}{ }^{-}$is mainly due to salt contamination present on the electrode surface which were not completely removed with DMC solvent. The $\mathrm{CH}_{2}{ }^{-}$and $\mathrm{CO}_{3}{ }^{-}$ion profiles can indicate the presence of organic carbonate species in the SEI layer. Due to possible interferences in the mass spectra of certain ions having very close masses, two signals $\left(\mathrm{CO}_{3}{ }^{-}\right.$ and $\mathrm{CO}_{2}{ }^{-}$) were used to probe carbonate species present in the SEI layer. The $\mathrm{CO}_{3}{ }^{-}$(mass 59.98) is difficult to be separated from $\mathrm{SiO}_{2}{ }^{-}$ having a very similar mass (mass 59.96) and appears as a shoulder of the $\mathrm{SiO}_{2}{ }^{-}$peak (not shown here). Although very similar mass values of $\mathrm{CO}_{2}{ }^{-}$and $\mathrm{SiO}^{-}$signals (43.98 for $\mathrm{CO}_{2}{ }^{-}$and 43.97 for $\mathrm{SiO}^{-}$), the peaks are clearly separated. Peak separation in mass spectra is improved for small mass values (in order to keep mass resolution given by $\mathrm{M} / \mathrm{M}$ constant), thus the separation of $\mathrm{CO}_{2}{ }^{-}$and $\mathrm{SiO}^{-}$is better than the $\mathrm{SiO}_{2}{ }^{-}$and $\mathrm{CO}_{3}{ }^{-}$mass peaks. Fig. 5b clearly shows that $\mathrm{CO}_{2}{ }^{-}$signal follows $\mathrm{CO}_{3}{ }^{-}$signal, indicating that there is no significant interference of $\mathrm{SiO}_{2}{ }^{-}$signal in $\mathrm{CO}_{3}{ }^{-}$depth profiles. Moreover, $\mathrm{CH}_{2}{ }^{-}$depth profile follows the $\mathrm{CO}_{3}{ }^{-}$and $\mathrm{CO}_{2}{ }^{-}$carbonate species profiles indicating that organic carbonate species are likely to be formed on the electrode surface, as already suggested by XPS analysis.

The Li-Si alloying/de-alloying reactions leading to Si structural changes are expected to occur independently of the nature of the electrolyte, contrary to the SEI layer for which the composition is highly dependent on solvent and salt nature. ToF-SIMS depth profiles of $\mathrm{Si}$ electrode cycled in EC:DMC (1:1)/LiPF $61 \mathrm{M}$ clearly show that changing electrolyte has no incidence on the structure of cycled electrodes. The same structural modifications described for a-Si:H electrodes cycled in $\mathrm{PC} / \mathrm{LiClO}_{4} 1 \mathrm{M}$ are observed. Only attenuation of $\mathrm{SiO}_{2}{ }^{-}$maximum intensity is more significant in EC:DMC-based electrolyte (from 20,000 to 6000 counts), while $\mathrm{SiO}_{2}$ - etching time length increases of the same amount (from $20 \mathrm{~s}$ (dashed arrow) to $\sim 160-110 \mathrm{~s}$ (solid arrow). The ion profiles corresponding to SEI layer species $\left(\mathrm{Li}^{-}, \mathrm{CH}_{2}{ }^{-}, \mathrm{CO}_{2}^{-}, \mathrm{CO}_{3}{ }^{-}\right.$, $\mathrm{LiF}^{-}$and $\mathrm{PF}_{6}{ }^{-}$) started to be collected before $\mathrm{Fe}_{2}{ }^{-}$signal, indicating that the electrode surface has been modified by the SEI layer. The $\mathrm{Li}^{-}$ion profile (Fig. 5c) is quite similar to that observed on the Fig. $5 b$ collected under the same operating conditions. A small shoulder of $\mathrm{Li}^{-}$profile before reaching the maximum of the intensity for the a-Si:H cycled in EC:DMC-based electrolyte (Fig. 5c) is also observed as shown previously (Fig. 5b). The products of salt reduction and contamination given by the $\mathrm{LiF}^{-}$and $\mathrm{PF}_{6}{ }^{-}$, respectively, are detected on the electrode surface. The $\mathrm{PF}_{6}{ }^{-}$maximum intensity is observed at the outer layer surface of the electrode and then it rapidly declines, showing that DMC used for sample rinsing was unable to remove completely the salt contamination. The $\mathrm{LiF}^{-}$signal maximum intensity is reached at the maximum of the $\mathrm{Li}^{-}$intensity (see black dashed arrow), indicating that $\mathrm{LiF}$ is closer to the silicon oxide/silicon interface (inner part of the SEI layer), while maximum intensity of the $\mathrm{CO}_{3}{ }^{-}$and $\mathrm{CO}_{2}{ }^{-}$ion profiles (carbonate species) appear in the same region as the $\mathrm{Li}^{-}$shoulder (outer part of the SEI layer). Compared to the a-Si:H cycled in PCbased electrolyte (Fig. 5b), the ToF-SIMS ion profile performed on the a-Si:H electrode cycled in EC:DMC-based electrolyte (Fig. 5c) exhibits a lower intensity of carbonate (decrease from 2000 to 300 and from 400 to 60 counts for the $\mathrm{CO}_{3}{ }^{-}$and $\mathrm{CO}_{2}{ }^{-}$ions, respectively) 
indicating lower concentration of carbonate species in the SEI layer.

\subsubsection{Pristine and (de)lithiated SiNW}

Fig. 6 shows ToF-SIMS depth profiles (negative ions: $\mathrm{SiO}_{2}{ }^{-}, \mathrm{Si}_{3}{ }^{-}$ and $\mathrm{CsSi}^{-}$) for pristine SiNWs deposited on TiN/Ti/stainless steel substrate. The depth profiles of ions characteristic of the SEI layer $\left(\mathrm{Li}^{-}, \mathrm{CH}_{2}{ }^{-}, \mathrm{CO}_{2}{ }^{-}, \mathrm{CO}_{3}{ }^{-}, \mathrm{ClO}_{4}{ }^{-}, \mathrm{LiF}^{-}\right.$and $\left.\mathrm{PF}_{6}{ }^{-}\right)$are presented in Fig. $6 \mathrm{~b}$ and $\mathrm{c}$ for SiNW cycled in PC- and EC:DMC-based electrolytes, respectively.

Due to the high thickness of the SiNW layer grown on the stainless steel substrate $(30 / \mathrm{Lm})$, the sputtering was not performed through the whole thickness of the SiNW film (Fig. 6a). As aforementioned using $75 \%$ of the maximum intensity of the $\mathrm{SiO}_{2}{ }^{-}$and $\mathrm{Si}_{3}{ }^{-}$signals to define $\mathrm{SiO}_{2}$ and $\mathrm{Si}^{0}$ regions (see solid arrows) in pristine SiNW (Fig. 6a), results in the appearance of a gap between these two regions, because of increased roughness associated with wire-like structure. Moreover, the Si disordered wire-like structure (Fig. 2c) significantly affects the $\mathrm{Si}_{3}{ }^{-}$and $\mathrm{SiO}_{2}{ }^{-}$ion depth profiles, as it will be described later. As previously observed in a-Si:H thin films, in the very first seconds of sputtering the $\mathrm{SiO}_{2}{ }^{-}$signal intensity increases and reaches a maximum after $\sim 20 \mathrm{~s}(10,000$ counts), indicating that $\mathrm{SiO}_{2}$ is mainly present on the surface of $\mathrm{Si}$ nanowires. However in a case of the SiNW sample, during the following seconds of sputtering the $\mathrm{SiO}_{2}{ }^{-}$profile smoothly declines to reach a plateau. After $300 \mathrm{~s}$ of sputtering time, the $\mathrm{SiO}_{2}{ }^{-}$and $\mathrm{Si}_{3}{ }^{-}$signals become parallel, indicating that the silicon oxide layer covers the Si nanowires all along their length (in the performed range of sputtered-layer thickness). This is in contrast to the a-Si:H thin film (Fig. 5a), where only the outer part of the Si film was covered by the native silicon oxide due to exposure to ambient air resulting in spontaneous oxidation. The $\mathrm{Cs}^{+}$ions implanted in silicon during sputtering were also detected as a $\mathrm{CsSi}^{-}$signal. When the $\mathrm{SiO}_{2}{ }^{-}$signal reaches its minimum value the $\mathrm{CsSi}^{-}$signal reaches its maximum intensity and becomes parallel to the $\mathrm{Si}_{3}{ }^{-}$signal. This indicates that silicon oxide is mainly located onto the Si nanowire surface.

Fig. 6b shows ToF-SIMS negative ion depth profile of SiNWs after one complete $\mathrm{CV}$ in $\mathrm{PC} / \mathrm{LiClO}_{4} 1 \mathrm{M}$ at $20 / \mathrm{LV} \mathrm{s}^{-1}$, where two main modifications of the electrode can be observed. The first modification is in the shape of the $\mathrm{SiO}_{2}{ }^{-}$and $\mathrm{Si}_{3}{ }^{-}$signals and the second is related to the appearance of new compounds $\left(\mathrm{Li}^{-}, \mathrm{CH}_{2}{ }^{-}, \mathrm{CO}_{2}{ }^{-}\right.$, $\mathrm{CO}_{3}{ }^{-}, \mathrm{ClO}_{4}{ }^{-}$) corresponding to the formation of the SEI layer. In contrast to the pristine $\mathrm{SiNWs}$, the $\mathrm{SiO}_{2}{ }^{-}$and $\mathrm{Si}_{3}{ }^{-}$ion profiles in cycled SiNWs do not cross each other, which indicates that a thick SEI-layer covers the nanowires all along their length and $\mathrm{SiO}_{2}$ signal is always more intense than $\mathrm{Si}_{3}{ }^{-}$signal. Moreover, a very high intensity of the $\mathrm{Li}^{-}$signal, as compared to the low intensity of the signals characteristic of $\mathrm{SiNW}$ region $\left(\mathrm{SiO}_{2}{ }^{-}\right.$and $\mathrm{Si}_{3}{ }^{-}$profiles), also indicates the presence of a thick SEI layer, which is in agreement with the SEM (Fig. 2d) and XPS results. Meanwhile, the $\mathrm{Li}^{-}$ion profile reaches the maximum intensity after around $\sim 400 \mathrm{~s}$ of sputtering and thereafter smoothly declines to the same intensity value as the $\mathrm{SiO}_{2}{ }^{-}$signal after $1400 \mathrm{~s}$ of sputtering. Thus, no characteristic features of the SEI as those of the cycled a-Si:H thin films (Fig. 5b) and attributed to "matrix effects", can be observed in cycled SiNW. The high intensity $\mathrm{Li}^{-}$signal confirms that the SEI layer extends all along the NW length.

As described before in Fig. 5b, a very intense $\mathrm{ClO}_{4}{ }^{-}$signal observed during the first few seconds of the sputtering indicates the presence of electrolyte contamination on the SiNW electrode surface, not completely removed by rinsing with DMC solvent. This result is in agreement with the XPS analyses where $\mathrm{Cl}$ contamination (signal in the $\mathrm{Cl} 2 \mathrm{p}$ spectrum) was found on the surface of SiNW after cycling (Fig. 4). In addition, the $\mathrm{CO}_{3}{ }^{-}$and $\mathrm{CO}_{2}{ }^{-}$signals were used to probe carbonate species in the SEI layer. For the cycled SiNWs, the $\mathrm{CO}_{2}{ }^{-}$signal (principally recorded for checking the $\mathrm{CO}_{3}{ }^{-}$signal reliability) becomes crucial, since charging effects are significant for SiNWs (mass peak broadening and lower mass resolution). In Fig. $6 \mathrm{~b}$ the $\mathrm{CO}_{2}{ }^{-}$in-depth concentration profile follows the $\mathrm{CO}_{3}{ }^{-}$signal, indicating no significant interference of the $\mathrm{SiO}_{2}{ }^{-}$and $\mathrm{CO}_{3}{ }^{-}$signals (having very similar masses as aforementioned). During the first $\sim 200 \mathrm{~s}$ of sputtering, both the $\mathrm{CO}_{3}{ }^{-}$and $\mathrm{CO}_{2}{ }^{-}$signals are much more intense than the $\mathrm{SiO}_{2}{ }^{-}$signal, indicating the presence of a carbonate layer onto the SiNWs surface. The intensity of the $\mathrm{CO}_{3}{ }^{-}$signal is one order of magnitude lower than in cycled a-Si:H thin film. Both carbonate signals follow the $\mathrm{Li}^{-}$profile. Moreover, the $\mathrm{CH}_{2}{ }^{-}$depth profile follows the $\mathrm{Li}^{-}, \mathrm{CO}_{3}{ }^{-}$and $\mathrm{CO}_{2}{ }^{-}$ ion profiles indicating that organic carbonate species are likely to be formed on the electrode surface, as already observed by XPS.

After one complete CV in EC:DMC-based electrolyte moderate changes are observed in the shape of the $\mathrm{SiO}_{2}{ }^{-}$and the $\mathrm{Si}_{3}{ }^{-}$ion profiles of the cycled SiNWs (Fig. 6c) compared to pristine SiNWs (Fig. 6a). The $\mathrm{SiO}_{2}{ }^{-}$signal reaches its maximum at $\sim 30 \mathrm{~s}(8000$ counts) compared to $\sim 20 \mathrm{~s}(10,000$ counts) for pristine SiNW. The $\mathrm{Si}_{3}{ }^{-}$signal remains almost unchanged after cycling, indicating that a very thin SEI layer is formed on the SiNWs surface. The intensities of the $\mathrm{Li}^{-}, \mathrm{CO}_{3}{ }^{-}$and $\mathrm{CO}_{2}{ }^{-}$signals corresponding to products of electrolyte decomposition (SEI layer) are lower than for the SiNWs cycled in $\mathrm{PC} / \mathrm{LiClO}_{4} 1 \mathrm{M}$, indicating the formation of a thinner SEI layer. Meanwhile, the intersection between the $\mathrm{SiO}_{2}{ }^{-}$and $\mathrm{Si}_{3}{ }^{-}$ signals is observed at slightly longer etching times (100 s) as compared to pristine SiNW (120 s), confirming the formation of a thin SEI layer, in contrast with the thick SEI layer formed on the SiNW electrode after cycling in PC-based electrolyte. Following the $\mathrm{PF}_{6}{ }^{-}$ signal (indicator of the level of contamination by salt after cycling) it can be concluded that this inorganic contamination is mainly observed at the extreme surface of SiNWs electrodes.

According to the ToF-SIMS results, a thicker SEI layer is formed on the surface of SiNW electrode after cycling (1CV) in $\mathrm{PC} / \mathrm{LiClO}_{4}$ $1 \mathrm{M}$ than in EC:DMC (1:1)/LiPF $1 \mathrm{M}$ electrolyte, independently of the degree of crystallisation and morphology of silicon electrodes (crystalline SiNW or a-Si:H thin films). The amount of carbonate at the silicon thin film surface is higher after cycling in $\mathrm{PC} / \mathrm{LiClO}_{4} 1 \mathrm{M}$.

\section{Conclusions}

After one complete CV a full coverage SEI layer was formed on a$\mathrm{Si}: \mathrm{H}$ and SiNW surfaces using two distinct electrolytes $\left(\mathrm{PC} / \mathrm{LiClO}_{4}\right.$ $1 \mathrm{M}$ and $\mathrm{EC}: \mathrm{DMC}_{\mathrm{LiPF}}$ 1M). SEI presence was confirmed by XPS analysis, where an increase in the $\mathrm{C} 1 \mathrm{~s}$ and $\mathrm{O} 1 \mathrm{~s}$ intensity signals and an appearance of new peaks associated with electrolyte reduction ( $\mathrm{Li} 1 \mathrm{~s}, \mathrm{~F}$ 1s, P 2p and $\mathrm{Cl} 2 \mathrm{p}$ ) were observed. Furthermore, strong attenuation of Si $2 p$ signal and displacement of XP spectra to higher energies related to charge effects confirms the presence of a SEI layer. SEM micrographs showed also modification of the electrode surface morphology. The use of $\mathrm{C} 1$ s or Si $2 p$ references to correct charge effects allowed to conclude that the organic part of the SEI layer is present at the outermost surface. XPS analysis also showed that the organic, outer-part of SEI-layer formed in PCbased electrolytes is thicker and richer in alkyl carbonate species, than that formed in EC:DMC-based electrolytes. Inorganic outermost part of SEI is mainly composed of salt decomposition products ( $\mathrm{LiCl}$ or $\mathrm{LiF}$ ) and $\mathrm{LiClO}_{4}$ or $\mathrm{LiPF}_{6}$ salt contamination not completely removed from electrode surface in washing process. These findings were confirmed by ToF-SIMS analysis, where a two-step lithium profile $\left(\mathrm{Li}^{-}\right.$ions) suggesting the presence of organic (in the outer surface) and inorganic (in the inner part of the layer) compoundlayer in the SEI layer was observed. This distribution of organic and inorganic parts in the SEI layer is also confirmed by the $\mathrm{CO}_{2}{ }^{-}$and $\mathrm{LiF}^{-}$signals, respectively. Furthermore, we have confirmed that $\mathrm{Si}$ 
electrode morphology greatly influences ToF-SIMS depth profile, making data interpretation difficult in a case of the SiNW electrode. From this point of view the comparative study with Si planar electrode $(\mathrm{a}-\mathrm{Si}: \mathrm{H})$ is very valuable to unravel the electrode/electrolyte interphase reactions taking place on SiNW surface. One can conclude that XPS and ToF-SIMS techniques can be successfully applied to detect and study the SEI layer on complex structures (SiNW) by using planar surface models.

\section{Acknowledgments}

The work was partially funded by Renault. Région Ile-de-France is acknowledged for partial support for the XPS and ToF-SIMS equipment.

The authors thank Sandrine Zanna and Antoine Seyeux from Chimie Paristech (LPCS) for the analyses and useful discussions about XPS and ToF-SIMS results, and Stephan Borensztajn from Laboratoire Interfaces et Systemes Electrochimiques (Université Pierre et Marie Curie) for the SEM and EDX analyses.

The authors are grateful to Anna Teyssot and Christophe Dudezert from Renault for fruitful discussions.

\section{References}

[1] R.A. Hugging, Journal of Power Sources 81-82 (1999) 13.

[2] D. Larcher, S. Beattie, M. Morcrette, K. Edström, J.-C. Jumas, J.-M. Tarascon, Journal of Materials Chemistry 17 (2007) 3759.

[3] H. Okamoto, Journal of Phase Equilibria and Diffusion 30 (1) (2009) 118.

[4] L. Tirado, Materials Science and Engineering R 40 (2003) 103.

[5] P. Limthongkul, Y.-I. Jang, N.J. Dudney, Y.-M. Chiang, Journal of Power Sources $119-121$ (2003) 604.

[6] M.N. Obrovac, L. Christensen, Electrochemical and Solid-State Letters 7 (5) (2004) A93.

[7] T.D. Hatchard, J.R. Dahn, Journal of The Electrochemical Society 151 (6) (2004) A838.

[8] J. Li, J.R. Dahn, Journal of The Electrochemical Society 154 (3) (2004) A156.

[9] W.J. Zhang, Journal of Power Sources 196 (2011) 877.

[10] C.K. Chan, H. Peng, G. Liu, K. McIlwrath, X.F. Zang, Y. Cui, Nature Nanotechnology 3 (2008) 31.

[11] C.K. Chan, R. Ruffo, S.S. Hong, Y. Cui, Journal of Power Sources 189 (2009) 1132

[12] C.K. Chan, R. Ruffo, S.S. Hong, R. Huggins, Y. Cui, Journal of Power Sources 189 (2009) 34.

[13] B. Laïk, D. Ung, A. Caillard, C.-S. Cojocaru, D. Pribat, J.-P. Pereira-Ramos, Journal of Solid State Electrochemistry 14 (2010) 1835.

[14] J.H. Ryu, J.W. Kim, Y.-E. Sung, S.M. Oh, Electrochemical and Solid-State Letters 7 (7) (2004) A306.

[15] A. Chagnes, J. Swiatowska, Lithium Ion Batteries - New Developments INTECH, in: I. Belharouak (Ed.), Electrolyte and solid-electrolyte interphase layer in lithium-ion batteries, 2012, pp. 145-172.

[16] I. Geoffroy, A. Chagnes, B. Carré, D. Lemordant, P. Biensan, S. Herreyre, Journal of Power Sources 112 (1) (2002) 191.

[17] A. Chagnes, B. Carré, P. Willmann, R. Dedryvère, D. Gonbeau, D. Lemordant, Journal of The Electrochemical Society 159 (9) (2003) A1255.

[18] P.B. Balbuena, Y. Wang, Lithium-Ion Batteries Solid Electrolyte Interphase, Imperial College Press, London, 2004

[19] Y.M. Lee, J.Y. Lee, H.-T. Shim, J.K. Lee, J.-K. Park, Journal of The Electrochemical Society 154 (6) (2007) A515.

[20] H. Nakai, T. Kubota, A. Kita, A. Kawadhima, Journal of The Electrochemical Society 158 (7) (2011) A798.

[21] W. Xu, S. Sai, S. Vegunta, J.C. Flake, Journal of Power Sources 196 (2011) 8583.

[22] Y.-C. Yen, S.-C. Chao, H.-C. Wu, N.-L. Wu, Journal of The Electrochemical Society 156 (2) (2009) A95.

[23] C. Cuong Nguyen, S.-W. Song, Electrochemistry Communications 12 (2010) 1593.

[24] B. Philippe, R. Dedryvere, J. Allouche, F. Lindgren, M. Gorgoi, H. Rensmo, D. Gonbeau, K. Edström, Chemistry of Materials 24 (2012) 1107.

[25] V. Etacheri, O. Haik, Y. Goffer, G.A. Roberts, I.C. Stefan, R. Fasching, D. Aurbach, Langmuir 28 (2012) 965.
[26] C.C. Nguyen, S.-W. Song, Electrochimica Acta 55 (2010) 3026

[27] H. Usui, Y. Kiri, H. Sakaguchi, Thin Solid Films 520 (23) (2012) 7006.

[28] J. Ś wiatowska-Mrowiecka, V. Maurice, S. Zanna, L. Klein, P. Marcus, Electrochimica Acta 52 (2007) 5644

[29] S. Tanuma, C.J. Powell, D.R. Penn, Surface and Interface Analysis 20 (1993) 77.

[30] D. Aurbach, M. Daroux, P. Faguy, E. Yeager, Journal of Electroanalytical Chemistry 297 (1991) 225.

[31] D. Aurbach, Y. Talyosef, B. Markovsky, E. Markevich, E. Zinigrad, L. Asraf, J.S. Gnanaraj, H.-J. Kim, Electrochimica Acta 50 (2004) 247.

[32] P.B. Balbuena, Y. Wang, Lithium-Ion Batteries: Solid-Electrolyte Interphase, Imperial College Press, London, 2004, pp. 91.

[33] L.-F. Cui, R. Ruffo, C.K. Chan, H. Peng, Y. Cui, Nano Letters 9 (2009) 491.

[34] M.N. Obrovac, L.J. Krause, Journal of The Electrochemical Society 154 (2) (2007) A103.

[35] L.B. Chen, J.Y. Xie, H.C. Yu, T.H. Wang, Journal of Applied Electrochemistry 39 (2009) 1157.

[36] M. Green, E. Fielder, B. Scrosati, M. Wachtler, J.S. Moreno, Electrochemical and Solid-State Letters 6 (5) (2003) A75.

[37] L.B. Chen, J.Y. Xie, H.C. Yu, T.H. Wang, Journal of Applied Electrochemistry 39 (2009) 1157-1162.

[38] V. Baranchugov, E. Markevich, E. Pollak, G. Salitra, D. Aurbach, Electrochemistry Communications 9 (2007) 796

[39] C.K. Chan, R. Ruffo, S.S. Hong, R.A. Huggins, Y. Cui, Journal of Power Sources 189 (2009) 34.

[40] B. Key, M. Morcrette, J.-M. Tarascon, C.P. Grey, Journal of The American Chemical Society 133 (2011) 503.

[41] R. Dedryvère, L. Gireaud, S. Grugeon, S. Laruelle, J.-M. Tarascon, D. Gonbeau, Journal of Physical Chemistry B 109 (2005) 15868.

[42] M. Herstedt, A.M. Andersson, H. Rensmo, H. Siegbahn, K. Edström, Electrochimica Acta 49 (2004) 4939.

[43] S. Laruelle, S. Pilard, P. Guenot, S. Grugeon, J.-M. Tarascon, Journal of The Electrochemical Society 151 (2004) A1202.

[44] J. Światowska, V. Lair, C. Pereira-Nabais, G. Cote, P. Marcus, A. Chagnes, Applied Surface Science 257 (2011) 9110.

[45] P. Verma, P. Maire, P. Novák, Electrochimica Acta 55 (22) (2010) 6332.

[46] E. Peled, D. Bar Tow, A. Merson, A. Gladkich, L. Burstein, D. Golodnitsky, Journal of Power Sources 97-98 (2001) 52.

[47] R. Fong, U. Vonsacken, J.R. Dahn, Journal of The Electrochemical Society 137 (1990) 2009.

[48] A.M. Andersson, K. Edström, Journal of The Electrochemical Society 148 (2001) A1100.

[49] J.-T. Li, J. Światowska, A. Seyeux, L. Huang, V. Maurice, S.-G. Sun, P. Marcus, Journal of Power Sources 195 (2010) 8251.

[50] J.-T. Li, J. Ś wiatowska, V. Maurice, A. Seyeux, L. Huang, S.-G. Sun, P. Marcus, Journal of Physical Chemistry C 115 (2011) 7012.

[51] J.F. Moulder, W.F. Stickle, P.E. Sobol, K.D. Bomben, Handbook of X-ray Photoelectron Spectroscopy, Perkin-Elmer Corp, Eden Prairie, MN, 1992.

[52] D. Aurbach, Nonaqueous Electrochemistry, Marcel Dekker Inc., New York, 1999.

[53] D. Aurbach, A. Zaban, Y. Gofer, Y. Ein Eli, I. Weissman, O. Chusid, O. Abramson, Journal of Power Sources 54 (1995) 76.

[54] K. Kanamura, S. Shiraishi, H. Tamura, Z.-I. Takehara, Journal of The Electrochemical Society 141 (1994) 2379.

55] P.M. Natishan, E. McCafferty, P.R. Puckett, S. Michel, Corrosion Science 38 (1996) 1043.

[56] P. Panjan, M. Cekada, M. Panjan, D. Kek-Merl, Vacuum 84 (2010) 209.

[57] B. Díaz, J. Światowska, V. Maurice, M. Pisarek, A. Seyeux, S. Zanna, S. Tervakangas, J. Kohlemainen, P. Marcus, Surface and Coatings Technology 206 (19-20) (2012) 3903.

[58] B. Díaz, J. Światowska, V. Maurice, A. Seyeux, B. Normand, E. Härkönen, M. Ritala, P. Marcus, Electrochimica Acta 56 (2011) 10516.

[59] B. Díaz, E. Härkönen, J. Światowska, V. Maurice, A. Seyeux, P. Marcus, M. Ritala, Corrosion Science 53 (2011) 2168

[60] B. Díaz, E. Härkönen, V. Maurice, J. Ś wiatowska, A. Seyeux, M. Ritala, P. Marcus, Electrochimica Acta 56 (26) (2011) 9609.

[61] J.-T. Li, V. Maurice, J. Światowska-Mrowiecka, A. Seyeux, S. Zanna, L. Klein, S.-G. Sun, P. Marcus, Electrochimica Acta 54 (2009) 3700

[62] J.-T. Li, J. Swiatowska, A. Seyeux, L. Huang, V. Maurice, S.-G. Sun, P. Marcus, Journal of Power Sources 195 (2010) 8251.

[63] J. Światowska-Mrowiecka, F. Martin, V. Maurice, S. Zanna, L. Klein, J. Castle, P. Marcus, Electrochimica Acta 58 (2008) 4257.

[64] H. Bryngelsson, M. Sjterndahl, T. Gustafsson, K. Edström, Journal of Power Sources 174 (2007) 970.

[65] M. Herstedt, D.P. Abraham, J.B. Kerr, K. Edström, Electrochimica Acta 49 (2004) 5097. 